\title{
Embracing Inclusivity through Pedagogical Practices: Case Studies from Singapore Science Lessons
}

\author{
Tang Wee Teo | ORCID: 0000-0002-7962-4304 \\ Corresponding author, \\ National Institute of Education, Nanyang Technological University, \\ 1 Nanyang Walk, 637616, Singapore \\ tangwee.teo@nie.edu.sg
}

Ching Yee Pua | orcid: 0000-0002-5542-3874

National Institute of Education, Nanyang Technological University,

1 Nanyang Walk, 637616, Singapore

lalalapcy@hotmail.com

Received: 12 June 2021 | Revised: 8 September 2021 | Accepted: 9 October 2021

\begin{abstract}
This paper examines the pedagogical practices in three case studies of elementary science lessons that took place in classrooms or laboratories to make connections to the discourse about inclusivity in science teaching. Using the Singapore Teaching Practice as a reference, we analyzed the pedagogical practices enacted during three lessons where specific intervention strategies were undertaken during the lessons to address the needs of students with dyslexia. Using event-oriented inquiry, nine (including one emergent) pedagogical practices were adapted by the science teachers. The findings also suggested differences in the outcomes from enacting the same pedagogical practices in different teaching situations. This study contributes to the literature by offering a situated definition of 'pedagogical practices', a dynamic construct in the existing literature, in the context of inclusive education. Suggestions on ways to adapt the nine pedagogical practices to enhance the reflexivity of teachers in inclusive science teaching are offered.
\end{abstract}




\section{Keywords}

pedagogical practices - inclusive science education - inclusivity - reflexivity

\section{Introduction}

Singapore's success in the international benchmark tests such as the Programme for International Student Assessment and Trends in International Mathematics and Science has evoked much international attention from educationists around the world who seek to understand 'what works'. The Singapore Teaching Practice (STP) is 'a model that makes explicit how effective teaching and learning is achieved in Singapore schools' (MOE, 2O21a). In the STP, 'pedagogical practices', a framework that captures fundamental teaching processes and teaching areas that can be applied to all subjects and all levels, constitutes a core component. The set of 24 pedagogical practices (MOЕ, 2021a) are categorized into four teaching areas: (a) assessment and feedback, (b) positive classroom culture, (c) lesson enactment, and (d) lesson preparation. The pedagogical practices are not subject or student specific; they can be adapted craftily by teachers even if they are focused on teaching the disciplinary content. Teachers are expected to adapt the pedagogical practices to address their students' needs. For instance, science teachers could 'set expectations and routines' (one of the pedagogical practices) in the science laboratory to ensure the safety of students when conducting experiments. They may apply a similar set of expectations and provide adapted support for students with dyslexia to ensure that they can participate and experience success with the spelling of scientific terms.

An enabler of success in teaching is the continual professional development of teachers, and such plans should be charted carefully to ensure that teachers invest quality time in developing their competencies in the relevant areas. In 2020, the Ministry of Education, Singapore, introduced SkillsFuture for Educators, a professional development roadmap for teachers to engage in the continual improvement of practices in six key areas: assessment literacy, inquiry-based learning, differentiated instruction, support for students with SEN, e-pedagogy, and character and citizenship education (MOE, 2O2O). This paper is based on a larger study that examines how science teachers in Singapore teach in classrooms where there are students diagnosed with special education needs (SEN). Specifically, it situates the discussion of pedagogical practices during science lessons where teachers are challenged to concurrently teach students who have and have not been diagnosed with SEN. Prior to this research, there have been no studies in Singapore that have focused on SEN 
in science classrooms. This study was inspired by the first author's academic curiosity about how pedagogical practices may play out in an inclusive science classroom. Unpacking such episodes could afford useful insights to other science teacher educators. The findings could also offer concrete examples to science teachers on how pedagogical practices could mediate the delivery of the science content for students with SEN in classrooms, even if the education system is seen to be successful as a whole.

In Singapore, students with SEN attend mainstream schools, and a variety of types of supports catering to different levels of learning needs are available. Specialized special needs schools are also available for students with SEN who need more support (MOE, 2O21b). According to Achieving Inclusion in Education (Disabled People's Association [DPA], 2016),

inclusive education is based on the premise that all individuals with disabilities have right to education, without discrimination or exclusion. It is an educational approach and philosophy that looks into how education systems can be modified or improved to respond to the diversity of learner. (p. 35)

An inclusive system requires the provision of accessible environments, appropriate teaching aids and equipment, child-centered curriculum, flexible teaching methods, having family and community involvement, quality teaching training, and well-supported teachers.

Consistent with global trends, the number of children diagnosed with developmental issues has increased over the years. In Singapore, the number of diagnosed cases increased from 2,500 to 4,400 from 2010 to 2014 , a $76 \%$ increase (MSF, 2016). The number of children diagnosed with autism spectrum disorder is 1 in 15 o children as compared to the 1 in 16o world average according (World Health Organisation, 2021). The Singapore government has expressed its commitment to inclusive education in several documents and policies including the five-year roadmaps articulated in the First Enabling Masterplan 2007-2011, Second Enabling Masterplan 2012-2016, and Third Enabling Masterplan 20172021 (National Council of Social Service, 2020). To highlight a few key policies related to SEN, the amendments to the Compulsory Education Act (MOE, 2O21C) have included children with moderate to severe SEN. With this amendment in place, it is compulsory for children of elementary school age with mild SEN who have the cognitive abilities and adequate adaptive skills to be schooled. Children with moderate to severe SEN will attend government-funded special education (SPED) schools.

The concept of 'inclusivity' is associated with the idea of participation. To be able to participate, students with SEN have to be given access so that they 
can present, collaborate with others to learn together, demonstrate abilities to achieve, and be recognized and accepted by others as part of the community (Florian \& Hawkins, 2011). The notion of an 'inclusive classroom', when referred to in this paper, is more systemic as it refers to learning contexts where students who have been diagnosed with one or more SEN go through the lesson with the other students. In order words, referring to a classroom as inclusive does not imply that the science teachers are always inclusive in their practices. Rather, inclusion is a systemic condition that allows for the majority of students with SEN to be mainstreamed in Singapore schools.

The structural conditions that give students with SEN access to mainstream classrooms thus do not necessarily indicate that all students will be able to participate equally if the other supporting conditions are not afforded to them when they enter the classroom. In our analysis, we focused on the parts of the lessons where the teachers in our study were perceived to have enacted inclusive practices based upon our feedback to a set of baseline lessons. The condition for well-distributed, if not equal, student participation was to first have the teachers give attention to the students with SEN, which then allowed for interaction between the teachers and students. From there, we examined the series of events that unfolded. The second level of analysis distilled the specific types of pedagogical practices that the teachers adapted in their interactions with students with SEN. We studied the manifestations of enacted pedagogical practices that led to the participation, achievement, recognition, and/or acceptance (Florian \& Hawkins, 2011) of the students with SEN in the class.

Science education research about SEN has been sparse, and studies focusing on teachers and teaching have been even fewer in comparison to other domains of work such as teaching strategies, student conceptions, and conceptual change and classroom learning (Lee, Wu, \& Tsai, 2009). Strategies that have been reported to enhance success in science learning for students with SEN include mnemonic instruction to strengthen memory (Mastropieri \& Scruggs, 1998) and hands-on activities (Scruggs \& Mastropieri, 1993). What we learnt from the few studies available is that guided instructions that provide proper scaffolding in lessons (e.g., inquiry based) are important for students with SEN to succeed. This illuminates the need to ensure that teaching strategies or techniques should be accompanied by appropriate pedagogies to allow for learning to take place effectively. 
Previously in Asia Pacific Science Education, a survey study on Singapore science teachers' positive views about their students with SEN, their self-efficacy views in teaching students with SEN, and inclusive science teaching practices was reported (Teo, 2020). The current paper drew upon the qualitative data collected from three case studies involving lesson videos of three science teachers who took part in the survey and was part of the larger study examining elementary science teachers and teaching during science lessons in classrooms in Singapore with more than one student diagnosed with dyslexia, a common SEN of students in Singapore and around the world (Dominguez \& Carugno, 2020; Dyslexia Association of Singapore, n.d.). To build on the previous discussions, this paper aims to contribute to the discourse about and understanding of how science teachers enacted various pedagogical practices to support students with SEN in an inclusive education system where children with SEN receive education in mainstream schools. Here, the discussion that we present from the case studies of three science teachers from the Singapore education system will resonate with many educationists around the world because many countries have an inclusive education policy and vested interest in the continual education of teachers to meet students' diverse needs.

Existing literature about pedagogical practices tends to refer to them as a set of skills informed by knowledge. However, 'pedagogical practices' as a construct lacks theorizing. This limits the discussion of pedagogical practices to a laundry list for the purpose of assessing teachers' competency levels during lesson observations. This paper will speak to science educators with limited understanding of how to engage pedagogical practices in science lessons to afford an inclusive environment for learning. Additionally, this paper will address the existing gap in the literature by first identifying the pedagogical practices observed during the three science lessons. Second, using these three lessons as case studies, we identified moments in the classroom or laboratory where other pedagogical practices can potentially be adapted to address inclusivity. Third, we theorize 'pedagogical practices' as they played out in these case study lessons. By so doing, we ground our work in the larger discourse of education that deepened the theoretical understanding of this construct. To this end, we addressed the following research questions in this paper:

1. What were the types of pedagogical practices that the science teachers adopted/adapted during the lessons with students with SEN?

2. In what ways did the enacted pedagogical practices promote inclusivity in the science lessons?

As 'pedagogical practices' is a key construct of this paper, we will elaborate on it in the next section before describing the methods of the study. 


\section{3}

\section{Pedagogical Practices}

The term 'pedagogy' is one of the most ill-defined terms in education, as its conception continues to grow in complexity over the years. The term 'pedagogical practices' has been used sparsely in the existing literature. When used, it has either not been defined in the paper or loosely referred to as the set of tools, methods, strategies, approaches, or 'things' that a teacher enacts during the lessons. In Sim's (2004) paper entitled 'The Personal as Pedagogical Practice', she referred to the teachers' use of self-disclosures of personal stories as 'an explicit teaching strategy' (p. 362) used for building a learning community where students learn, feel confident in the knowledge, talk openly, and realize the fun of learning. From this, we can infer that the conception of pedagogical practice is related to a teaching strategy that is informed by a teacher's personal experience that was turned into a form of tacit knowledge that becomes actionable. A similar idea was articulated in Rapoport's (2008) work examining the pedagogical practices of participants of an international program in Russia:

[T] he rationale of the study was to make sense of the knowledge and experiences obtained by international program alumni as well as their endeavors to convert the latter into pedagogical content knowledge and skills by providing the participants an opportunity to voice their beliefs, judgments, and sensations regarding the impact of their respective programs. (p. 227)

In other words, pedagogical practices are constitutive of knowledge, skills, and experiences sharped by a range of personal factors. In this case, the specific knowledge referred to is the well-established concept of pedagogical content knowledge (Shulman, 1996). Hennessy and Deaney (2009) further unpacked the term 'pedagogical practices':

We define the personal domain here in terms of pedagogical approaches and thinking (integrating both theoretical and practical insights as did Zwart et al. [2007]), and scrutinize practice in terms of planned and reported teaching and learning activities that developed the original pedagogical practices observed. (p. 623, emphasis in original)

We understand this excerpt to mean that pedagogical practice is a theoretically and practically informed view (which was not articulated in the other two studies) that contributes to the planning and implementation of the observed 
actions. In examining the discourse on inclusion in the Hong Kong education system, Chan and Lo (2017) raised the following critique:

This thinking [about integration that raises questions on equity and social justice] is perhaps reinforced by the traditional representation of special education in Hong Kong's educational discourse as a means to support children with 'disorders' rather than as a pedagogical practice to promote social justice and fight exclusion (Skidmore, 2002; Slee, 2011). (p. 716)

In their view, pedagogical practices have the potential to serve as a mechanism or tool to achieve inclusion.

\subsection{Our Meaning-Making of Pedagogical Practices}

The creation of pedagogical practices may comprise the performative act of teaching with the teachers' interpreted understandings of the purpose of education and broad education policies (interpretive pedagogy), personal experiences (tactical pedagogy), theoretical understandings from research, recognition of the expertise and agency of colleagues from whom they can harness resources (institutional pedagogy), and inquiry mind (inquiry pedagogy). The outcome of this purposeful and tactful interweaving of thoughts is a series or set of actions, words, and artefacts premised on rationality and careful deliberations. Due to a lack of clarity in the literature, we offer our definition of pedagogical practices as follows:

'Pedagogical practices' refers to a literal and symbolic moves, articulations, and objects, premised on a set of personal and professional attributes, to achieve educational goals, purposes, and outcomes.

The above definition encompasses the idea that the performative acts (Teo, 2013) of teachers during lessons embody pre-planned and impromptu decisions that teachers make during a lesson. In our work, the educational goals, purposes, and outcomes concern educational inclusivity.

Methods

4.1 Context of the Study

This study is part of a larger and inaugural research study about Singapore elementary school (Grades 1-6, ages 7-12) science teachers and science teaching. 
This paper reports on three lesson observations conducted at three separate classrooms or laboratories in two mainstream public and government-funded elementary schools. The case study lessons reported in this paper were enacted after the researchers provided feedback and suggestions to the teachers from observing a minimum of three baseline (non-intervention) lessons.

\subsection{Research Participants}

The three science teachers who participated in this study were between the ages of 25 and 40 at the time of the study. The schools at which they taught were public schools similar to the majority of other schools in Singapore in terms of student demographics, location among public residential estates, and academic achievement on national examinations. The teachers were conveniently sampled as personal contacts with the first author. The teachers were asked to identify one class with at least one student with dyslexia (the SEN with the highest frequency of occurrence) as a case study. Participation in the study was voluntary. Informed consent was obtained from the teachers prior to the start of the study. Student assent and parent consent were also obtained from the classes being observed. Alternative seating arrangements were made to ensure that students who did not give consent were excluded from the data collection.

Cindy was a beginning elementary school teacher who had just started teaching for a year at the time of the study. Cindy taught English and science in the school. She had completed a bachelor of science (education) and had no certified training in SEN. She had 15 Grade 4 (aged 10) students. Five of the students (four boys and one girl) had been diagnosed with dyslexia.

Sandy had been teaching for about 11 years at the time of the study. She was pursuing her master of education degree program and had no certified training in SEN. Sandy and Cindy were assigned as co-teachers of a Grade 4 science class. While Cindy taught 15 students, Sandy took charge of 16 students, of whom six were boys and 10 were girls. Five (three boys and two girls) had been diagnosed with dyslexia. At Cindy's and Sandy's school, there were assistant teachers, known as Allied Educators, who provided support to students with SEN. All Grade 4 students in the school who had been specifically diagnosed with dyslexia were assigned to this class, as the school leaders thought it would be easier for the teachers to address their specific learning need.

Melissa was an experienced teacher with 7 years of teaching experience at the time of the study. She had completed a master of education and had no certified training background in SEN. She was also a discipline teacher in the school. Her Grade 3 science class was one of the case studies. She did not have experience in teaching students with dyslexia prior to this study. In her class 
of 33 students ( 17 boys and 16 girls), there were two students (one boy and one girl) who were diagnosed with dyslexia.

\subsection{Data Collection}

For each teacher, lesson data collection was conducted six times throughout a school year. The lesson observations lasted one or two periods (30-6o minutes). We first conducted three baseline lesson observations to examine how the teachers taught science in the inclusive context. After the baseline data collection, the researchers had a discussion with the individual teachers to provide feedback and suggestions (see Table 1) on useful teaching strategies to address the needs of the students with dyslexia. Thereafter, the teachers were given a few weeks to internalize the information, deliberate over the suggestions, and incorporate the suggestions in their upcoming lessons. They communicated to the researchers the specific changes they were making. Three more lesson observations were conducted to examine the enactment of the interventions. All lessons were carried out in either a classroom or a science laboratory.

Two video cameras were placed in the room during data collection. One camera was positioned at the front of the room to focus on students' behavior and the whole-class situation. Another camera was positioned at the back of the room to focus on the teacher's behavior. Fourteen hours of lesson video were collected. However, the purpose of this paper was not to quantify the pedagogical practices enacted in the science classroom. Rather, we wanted to provide descriptive insights into how various pedagogical practices were enacted and the series of events that unfolded that alluded to diverse indicators of inclusion such as participation, collaboration, achievement, recognition

TABLE 1 Suggestions that were taken up by the teachers and implemented in the observed lesson

\section{Teacher Some suggestions for improvements}

Cindy Setting expectations for all students including students with SEN

Offer students opportunities to move around and engage in social interaction

Sandy Identifying a focus for the lesson (i.e., spelling, reading, understanding of concept)

Melissa $\quad$ Assign specific roles for students in group work and to rotate the roles so that each of them will have the opportunity to take responsibility for different tasks 
and/or acceptance. As such, we conducted a fine-grained analysis of 138 minutes of lesson videos, drawn from one lesson per case study teacher, to identify specific pedagogical practices enacted that showed inclusivity. Hence, we conducted event-oriented inquiry (Tobin, 2014) to look for relevant and specific episodes for illustrative purpose.

\subsection{Analysis}

To reiterate an earlier point, we had selected the episodes to illustrate how pedagogical practices were enacted in ways that addressed inclusivity. After identifying one lesson video from each case study teacher, we watched the lesson videos multiple times to identify lesson episodes that illuminated the intervention planned by the teacher. The intervention to be adopted was shared by the teacher with the research team prior to the lesson. In the selected episodes, we looked for evidence that showed the teacher (1) explicitly enacting the strategy that she had informed the research team about prior to the lesson and (2) interacting with the whole class and in relation to the student with dyslexia during the lesson. After going through the videos several times, we extracted episodes that clearly demonstrated the intervention and the series of relevant events that unfolded following the intervention. The episodes varied in duration from 10 seconds to 7 minutes. The lesson discourses in the videos were transcribed and actions were described to facilitate meaning-making of the pedagogical practices.

We adopted prescriptive coding using the list of pedagogical practices in the Singapore Teaching Practice to help us identify some of the practices that had been pre-identified as exemplary. The coding was done independently by the researchers and the findings were discussed to ensure complete alignment. However, we also identified a pedagogical practice that was not in the list and added it to the list of codes. Table 2 below shows the pedagogical practices used to code the episodes.

\section{$5 \quad$ Findings and Discussion}

In this section, we present the three cases separately and discuss the observed pedagogical practices. As mentioned earlier, we wanted to observe how the events unfolded upon the enactment of a pedagogical practice that was supportive of a student with SEN. As the episodes are connected, we decided to present the cases and the events as a whole to preserve the flow. Next, we provide our interpretive commentary on each case to answer the research 
TABLE 2 Teaching processes and pedagogical practices observed in the episodes

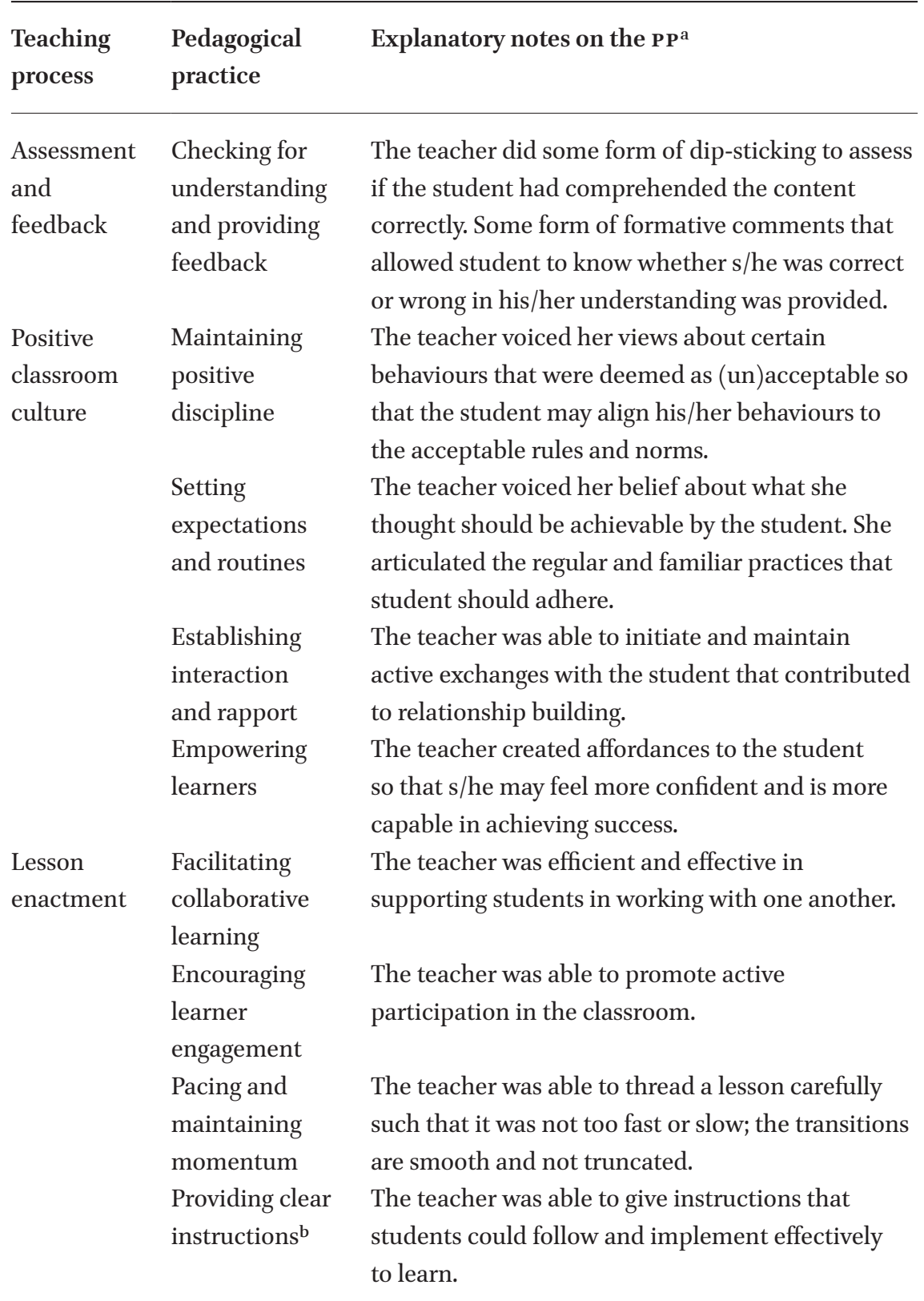

a Drawn from the episodes.

b An emergent pedagogical practice identified from the case study lesson data. 
questions. Here, we also identify other pedagogical practices that can potentially be adapted in an inclusive context. Last, we theories about the enactment of the pedagogical practices to ground the discussion in the theoretical underpinnings of inclusive science pedagogies.

\subsection{Case Study 1: Cindy}

The lesson below was the fourth lesson observation in Cindy's science class, which took place in the laboratory. The lesson involved a group activity where students were asked to record the distance of a torch and the height of shadows. Cindy adopted the recommendation to assign Nicholas (student diagnosed with dyslexia) the task of recording the measurements. Cindy thought that Nicholas was capable of achieving this task because it involved a minimal amount of numeral writing. Table 3 highlights the pedagogical practices enacted by Cindy as she prepared Nicholas to take on the role and monitored his performance during the lesson. Eight different pedagogical practices were enacted in the approximately 7-minute two-part episode.

\subsubsection{Interpretive Commentary}

Episode 1 A. As the students were doing group work for the first time, Cindy provided detailed instructions to students and assigned specific roles according to the numbers the students had been assigned. Nicholas, who was assigned Number 4, had to measure the height of the shadow as the position of the torch light was shifted. Notably, when Cindy commented that Nicholas was not paying attention, he said aloud that he was 'a stupid dumb dumb'. On hearing Nicholas' comment, Cindy immediately expressed her disagreement ('Nicholas, you are not'), retorted his point ('You are not stupid'), and showed displeasure over the comment ('[I] don't like you to say that.'). She continued to engage Nicholas by checking with him on his assigned task. Nicholas articulated it softly and Cindy checked with him on his confidence level. When Nicholas said, 'no', Cindy counter-proposed to him in asking if he could try. When Nicholas expressed doubts in his ability to complete the task, the following sequence of responses emerged: (1) asking Nicholas if he could try, (2) clarifying with Nicholas if he did not know or did not want to try, (3) productive provocation in asking Nicholas if he would just sit and do nothing, (4) telling Nicholas to put in effort to try, (5) telling Nicholas that she would be there to support him, and (6) confirming with Nicholas if he would put in the effort. With this series of responses, Nicholas finally said, 'fine' to mean that he would try. Nonetheless, Cindy reaffirmed his response in asking again, 'Is that okay?' Nicholas raised his voice to affirm his response. 


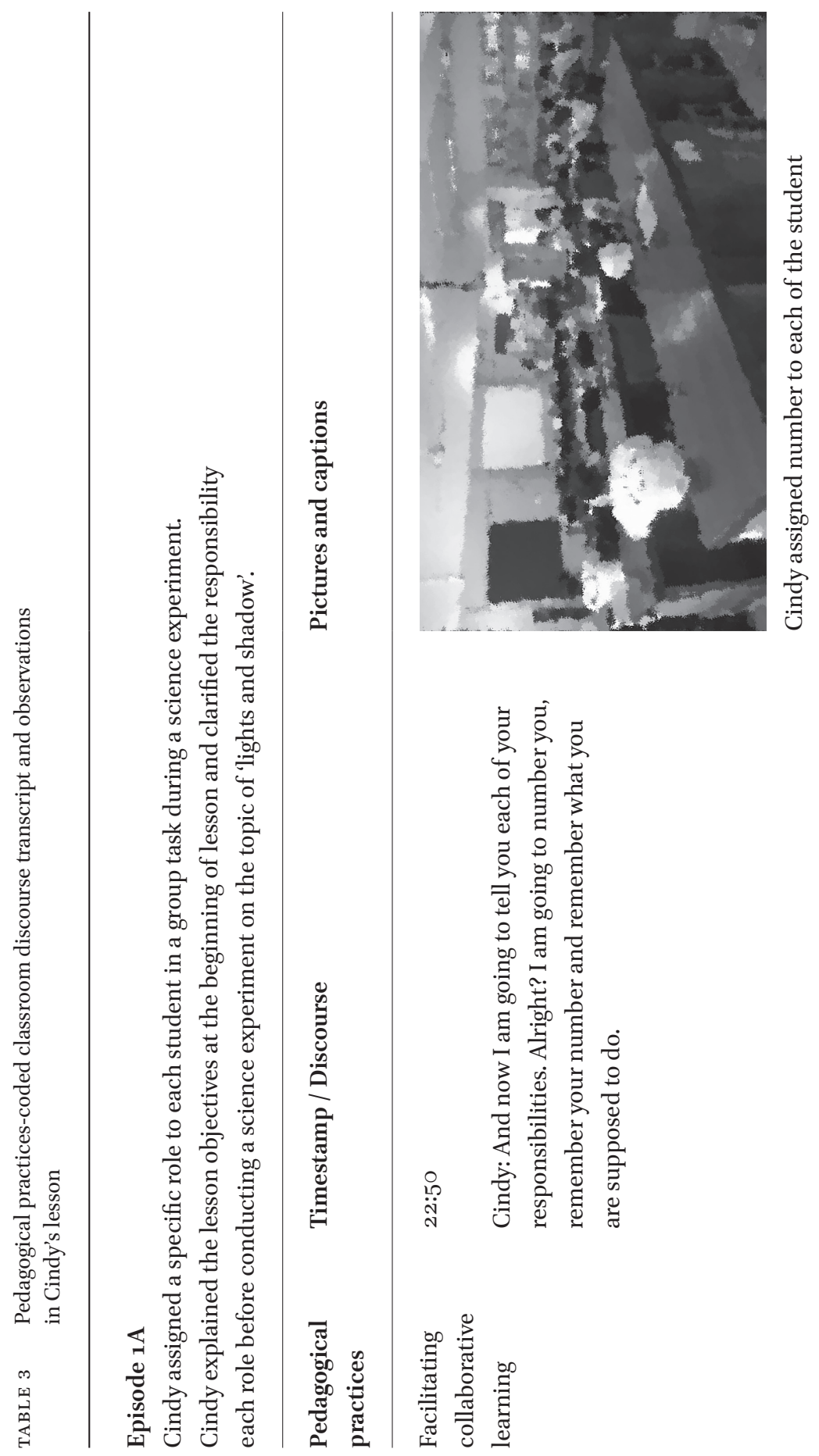




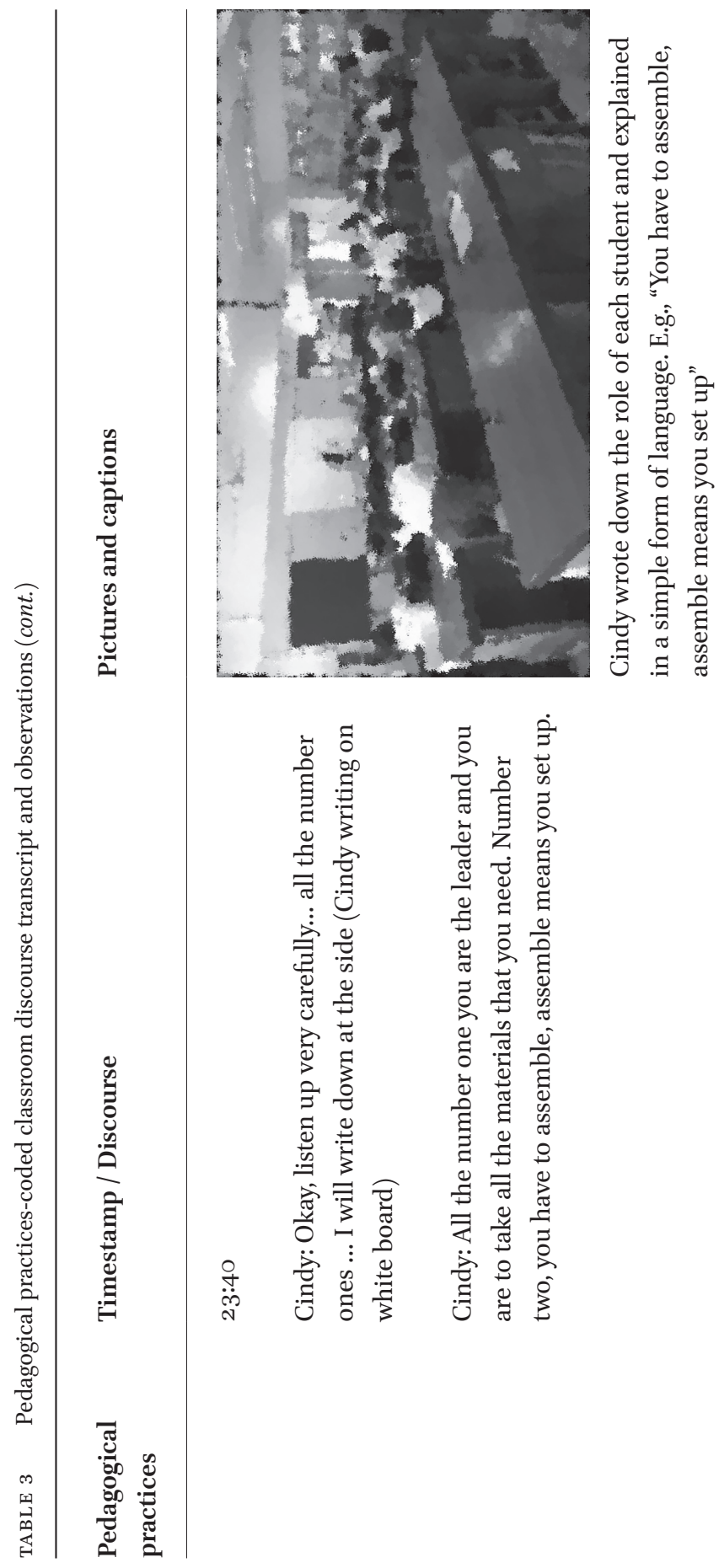




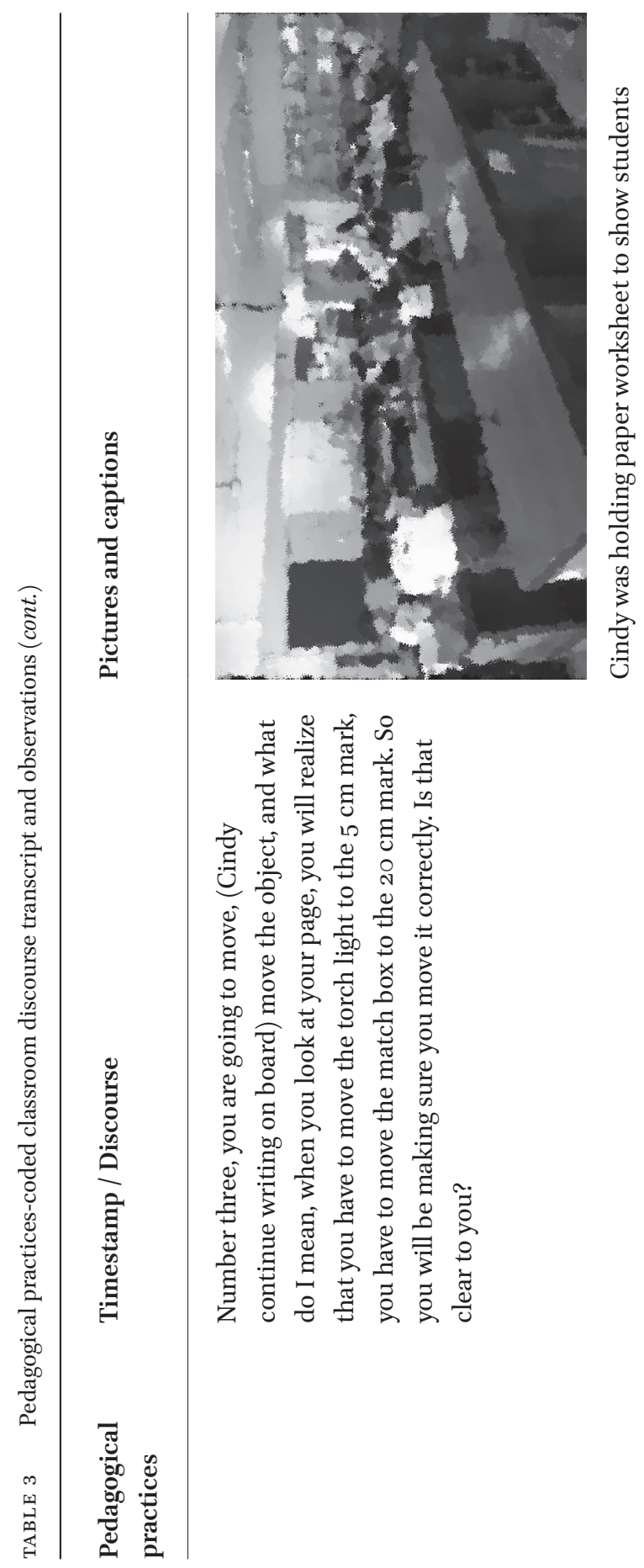




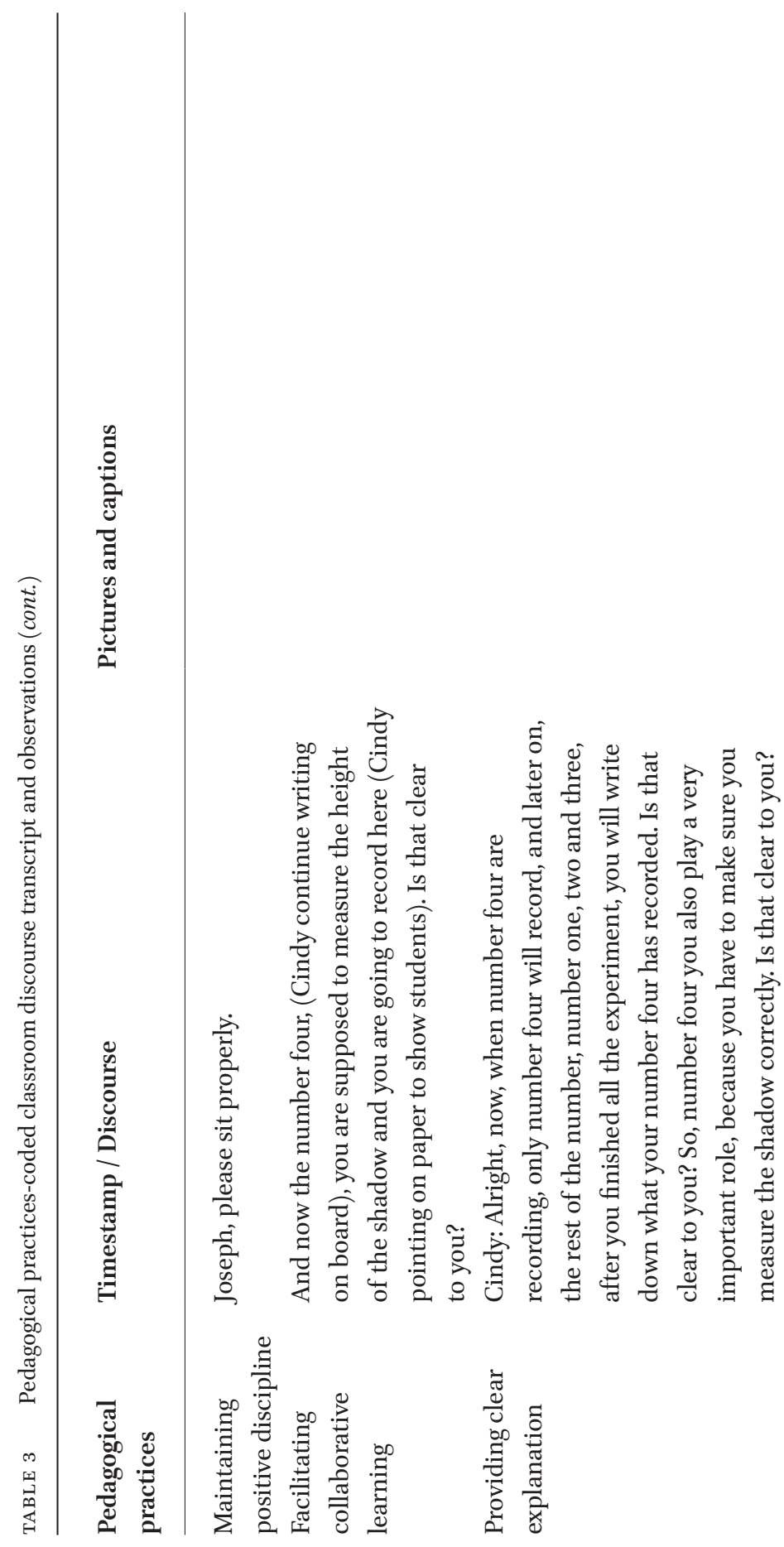




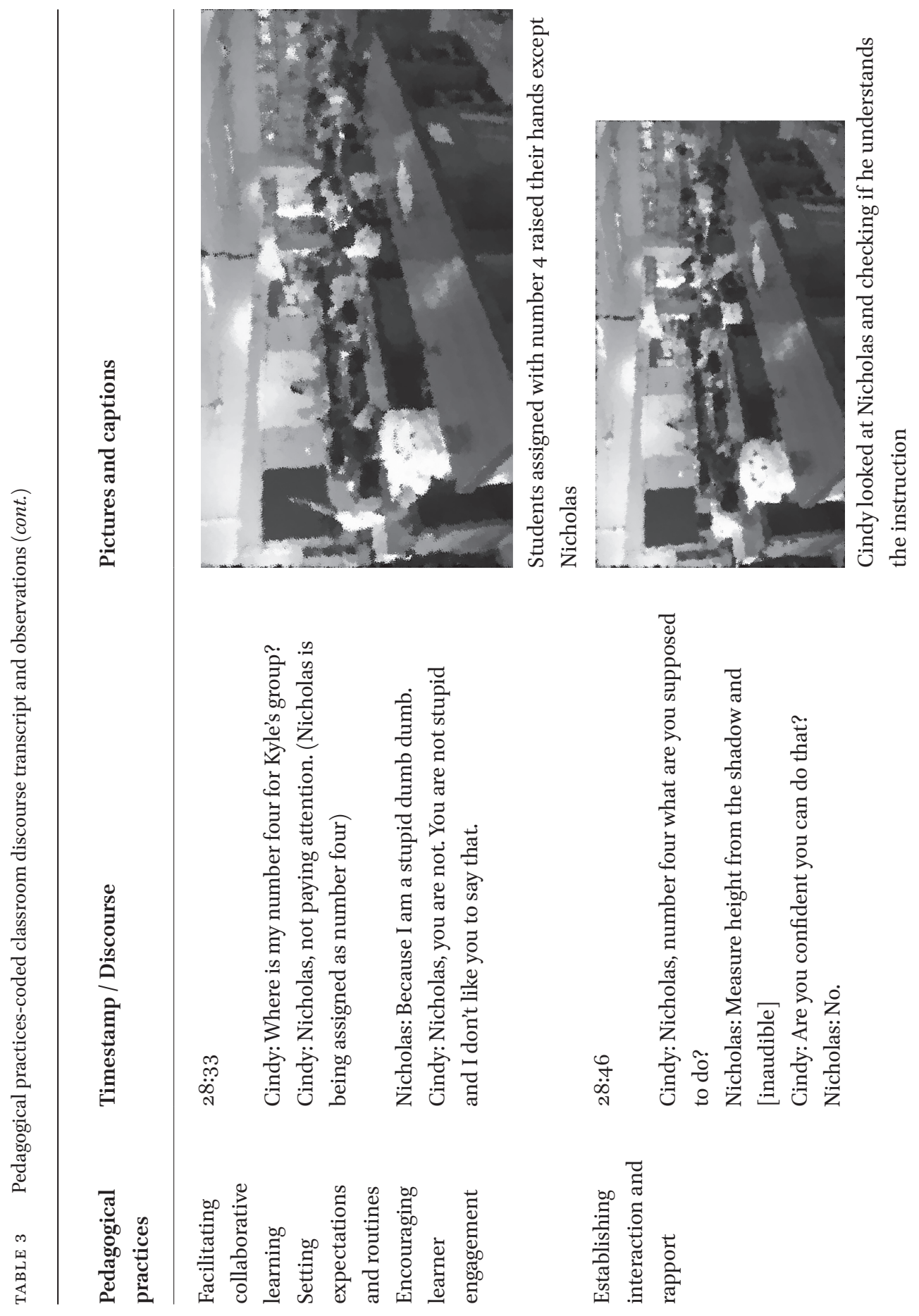




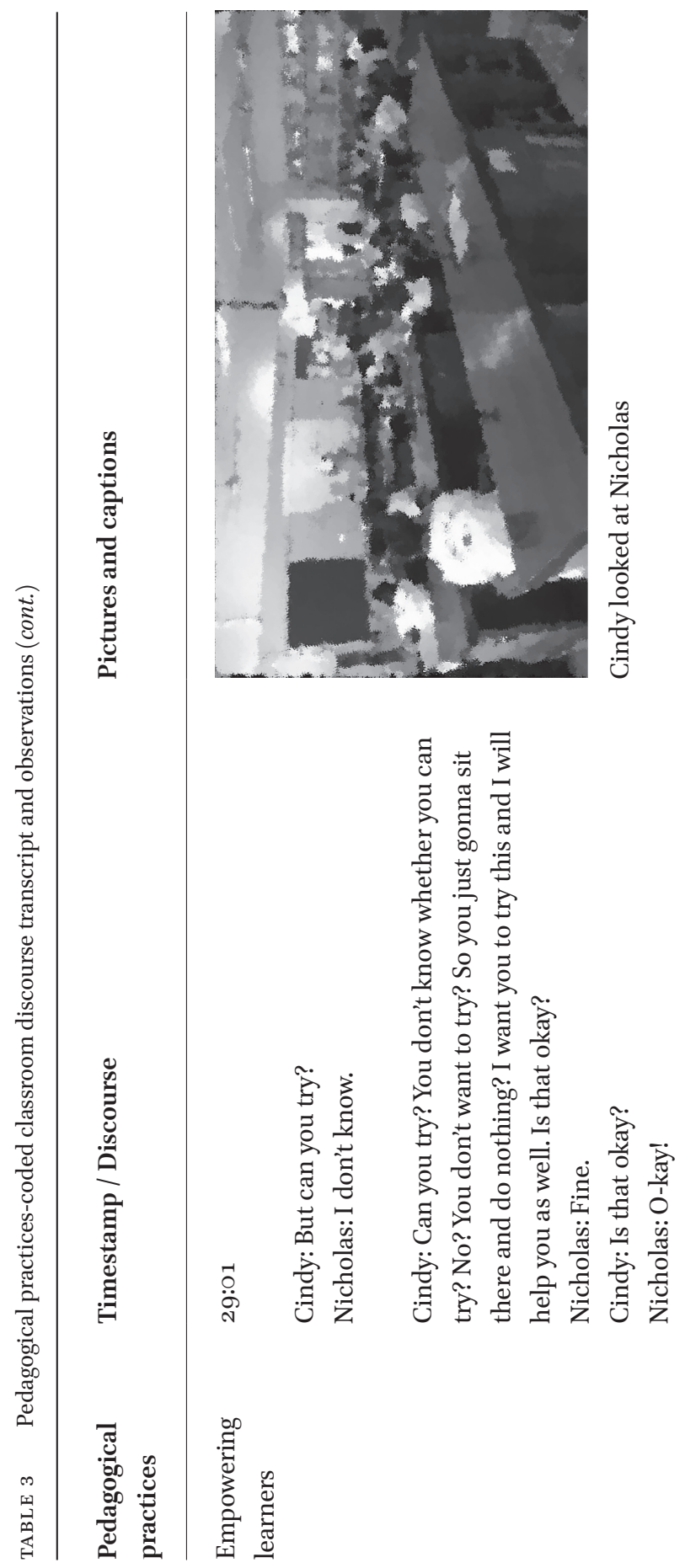




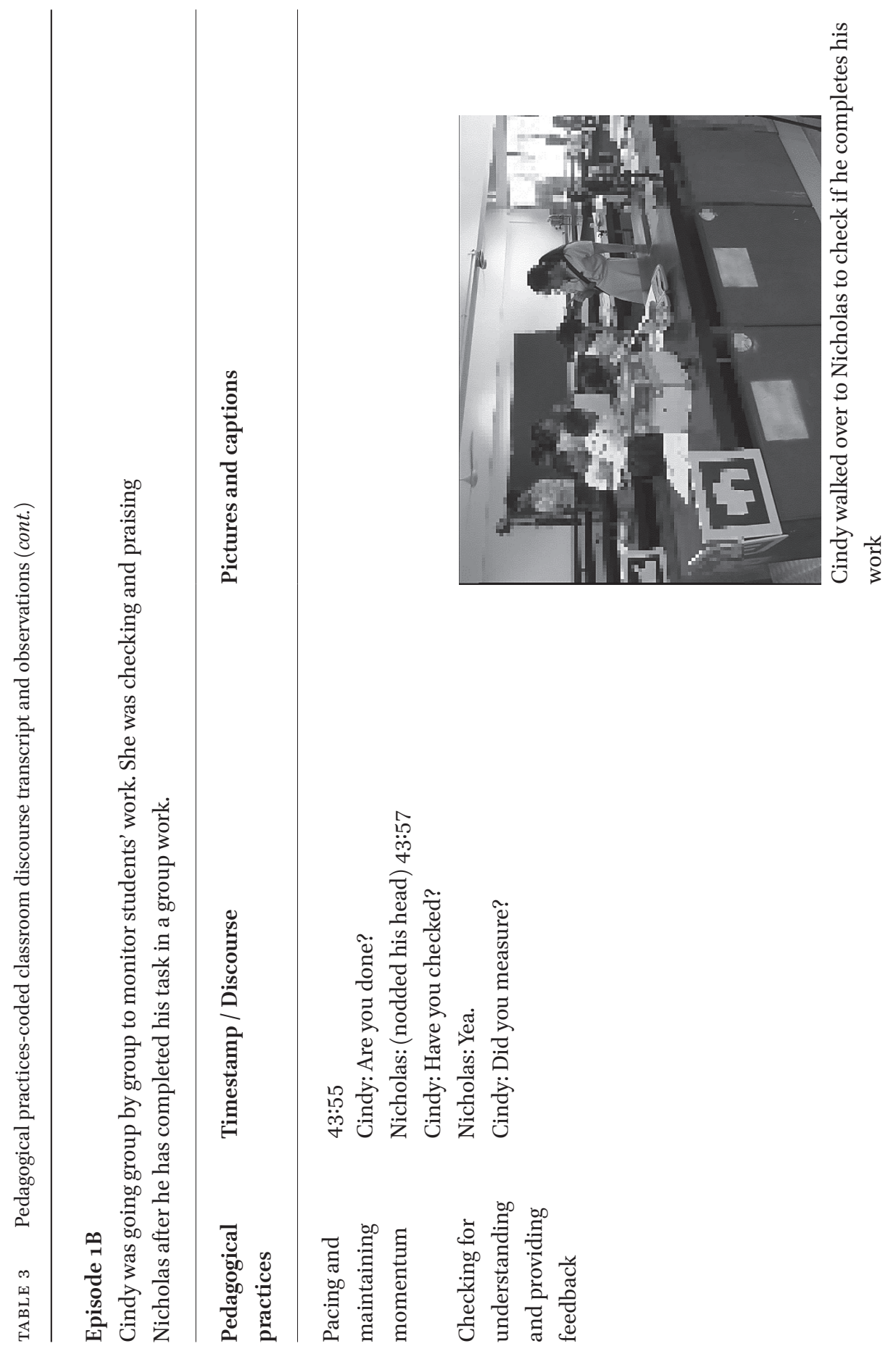




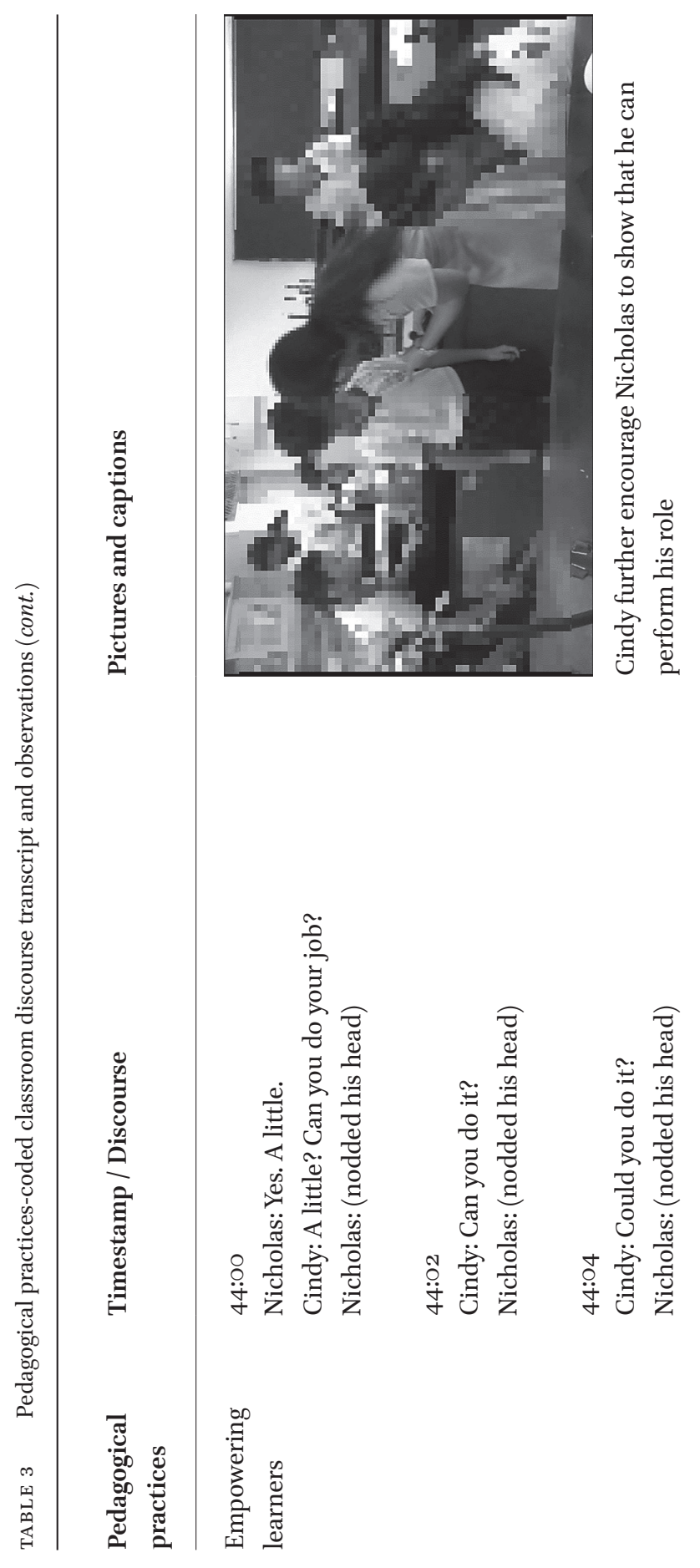




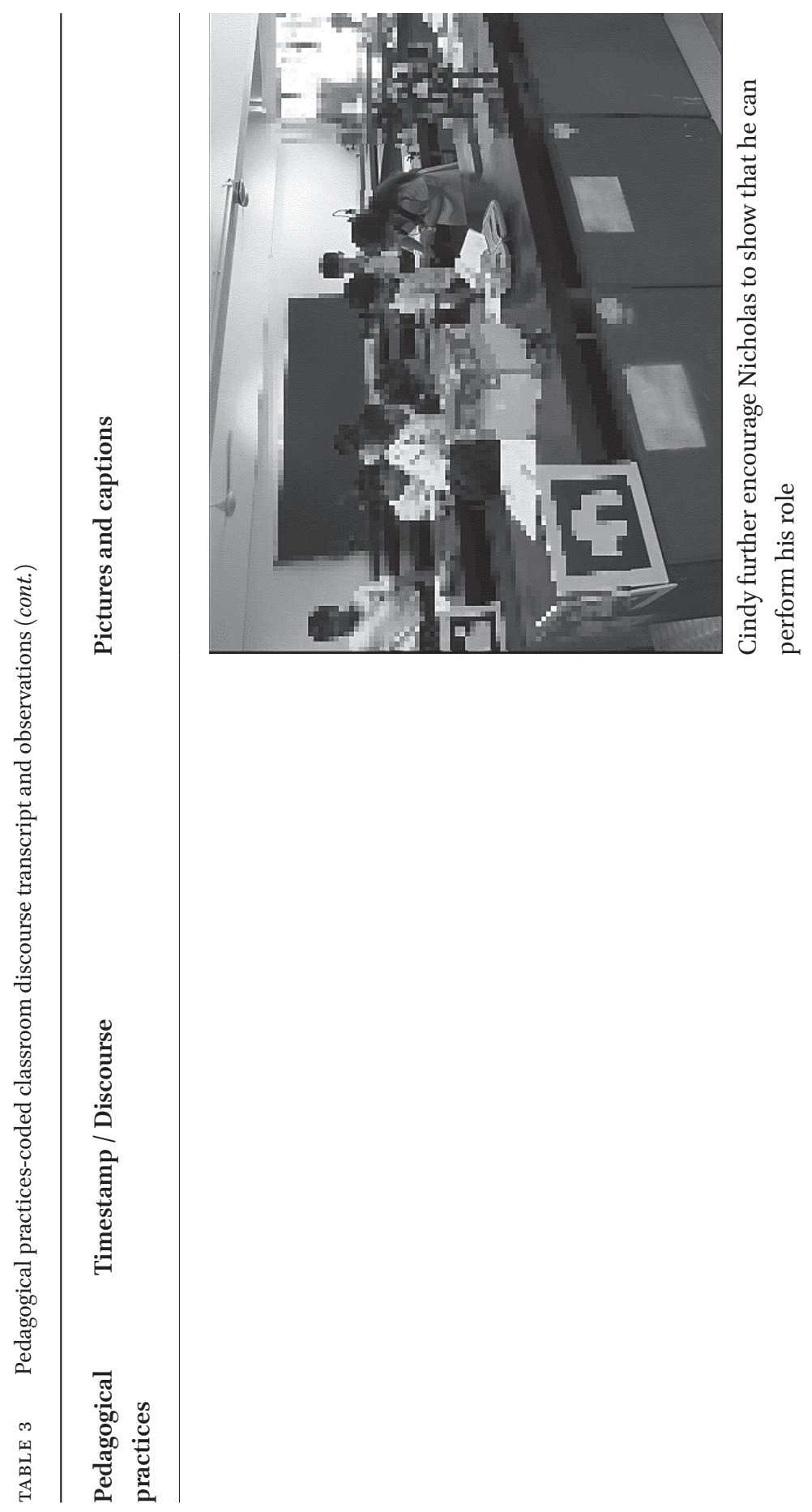




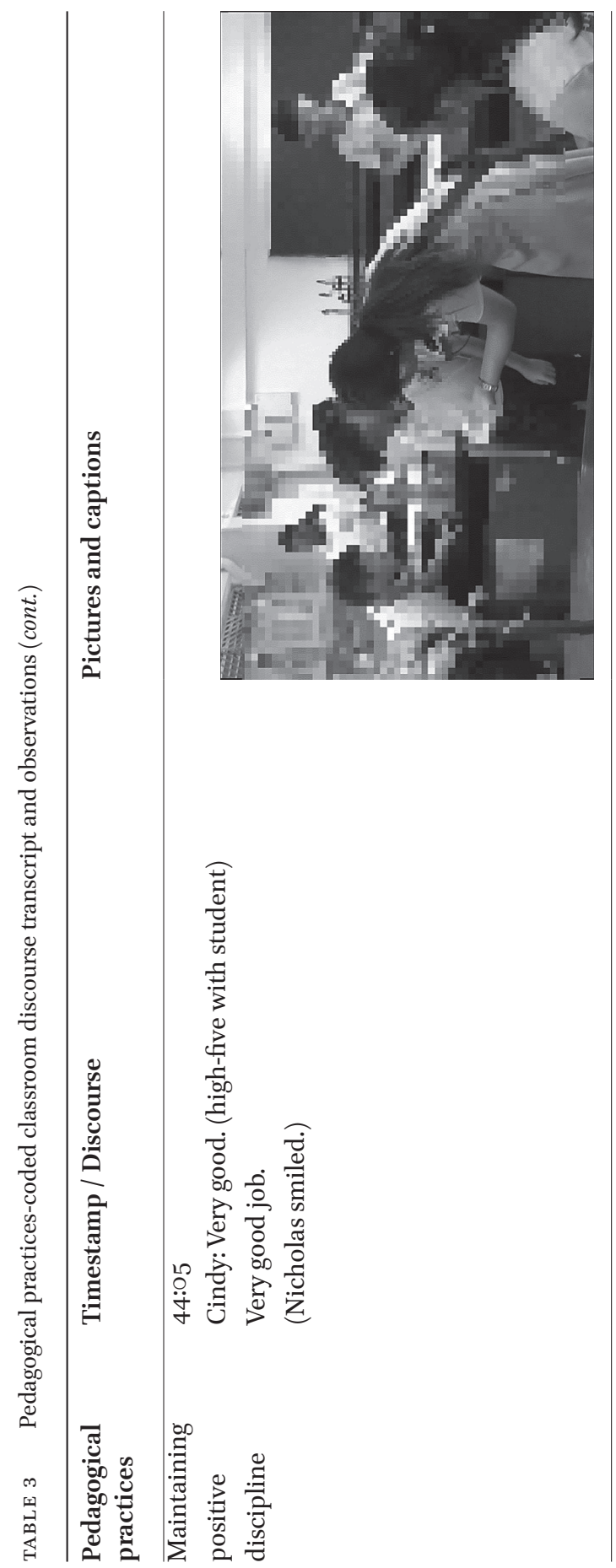


Episode $1 \mathrm{~A}$ illustrates the strategic pedagogical moves that Cindy had enacted to make the lesson inclusive for Nicholas. This was achieved by the symbolic 'Number 4' role that accompanied a set of responsibilities to the social group that he belonged. As a member of a group, Nicholas was accountable to his peers regarding their learning progress and output. The task was not onerous and was something that Nicholas could achieve without being hindered by his learning difficulty. However, Nicholas had to first overcome his lack of confidence as he had not had the experience of being accountable to anyone other than himself all this while. Instead of allowing him to wallow in self-pity or negotiate himself out of his role and responsibilities, Cindy asked a reflective toss question (Chin, 2006) and then encouraged him to own the challenge with the knowledge that she would be there to provide support if needed. In doing this, Nicholas had probably learnt that he could achieve within his means if he put in the effort and that he would not be able to get away from his responsibility by using his learning difficulty or poor selfperception as the reason.

Episode $1 B$. After the students had spent some time performing their group task, Cindy went over to Nicholas' group to check on the group's progress. Cindy first asked Nicholas if he had completed the task. This was to check that Nicholas was on task. When he nodded his head to signal a positive response, Cindy asked if he had checked his work. Again, she was ensuring that Nicholas had done his due diligence. This time, he verbally responded, 'Yea.' Cindy went on to ask Nicholas if he had done the measurement. The pedagogical practice enacted took a different twist, as Cindy's question was not generally about being on task; rather she was checking that he had performed a specific task. When Nicholas implied that he had done only part of the task, Cindy was not approving. Instead, of telling or reminding Nicholas that he should complete his task, she tossed the question to Nicholas in asking him if he could do what he was assigned to complete. Cindy was empowering Nicholas to take ownership of his role as a group member. When Nicholas simply nodded to signal that he could do it, Cindy reaffirmed Nicholas' response by asking him twice if he could complete the task. During this time, Cindy had bent her head and spoke in close proximity to Nicholas. He tilted his head to the side as if to avoid her close questioning. A few of his classmates watched as they spoke. The episode ended with Cindy praising Nicholas for agreeing to try and doing well for what he had completed. The high-five gesture made Nicholas smile.

\subsection{Case Study 2: Sandy}

The lesson below was the fourth lesson observation in Sandy's class, where she was getting the students to learn the words in the unit on light. According 
to Sandy, who had taught the same class last year, the students had problems learning the words, let alone explaining their ideas. Therefore, she decided that she would focus on getting students to recognize and spell the key terms. Her lessons typically involved reading (with syllabic highlights) and spelling in small notebooks that she would go around to check and stamp to acknowledge correctness. In this particular lesson, Sandy had given Alice, one of the students with dyslexia, the option to participate in the spelling lesson differently from the rest of the class. Table 4 highlights the pedagogical practices enacted by Sandy as she prepared Alice to participate in the spelling formative assessment.

\subsubsection{Interpretive Commentary}

Episode 2. Sandy asked the students if they wanted to participate in the spelling test. The students were excited as they shouted 'yes!' because they could each write their answers on a small whiteboard. Each of them was given a writing tool where they could show their spelt word to Sandy. Sandy instructed all students to turn their bodies to face the back of the class so that they would not see the word on the screen. However, before the spelling started, Sandy looked at Alice and repeatedly reassured her that she need not feel pressured to do the same. This was because she knew that Alice had difficulty with spelling. After Sandy read out aloud the first words, 'pass through', she looked at Alice again and gave her individual instructions to learn by copying the word on her whiteboard. Sandy's main goal for Alice was for her to learn the spelling and not to recall the spelling of the words. She walked around to check on individual students' spelling. As she walked around, she praised those who spelt the words correctly. She also corrected those who had spelt incorrectly by referring the student to the words on the screen behind them. This particular episode illustrates the differentiated instruction that she provided to students with the same lesson objective to have students learn how to spell key terms in science.

\subsection{Case Study 3: Melissa}

The lesson below was the fifth lesson observation in Melissa's class, which was on the topic of strength of materials. Similar to Cindy, Melissa had decided to take up the suggestion to assign explicit roles to students. In particular, she assigned Kevin, one of the two students with dyslexia in the class, the role of the data recorder. This was in response to our shared observation that Kevin would avoid the task of writing, which was typically undertaken by the two girls in his group. In this lesson, she paid attention to Kevin, to ensure that he contributed to the group work. Table 5 highlights the pedagogical practices enacted by Melissa as she prepared Kevin to participate in the group work. 


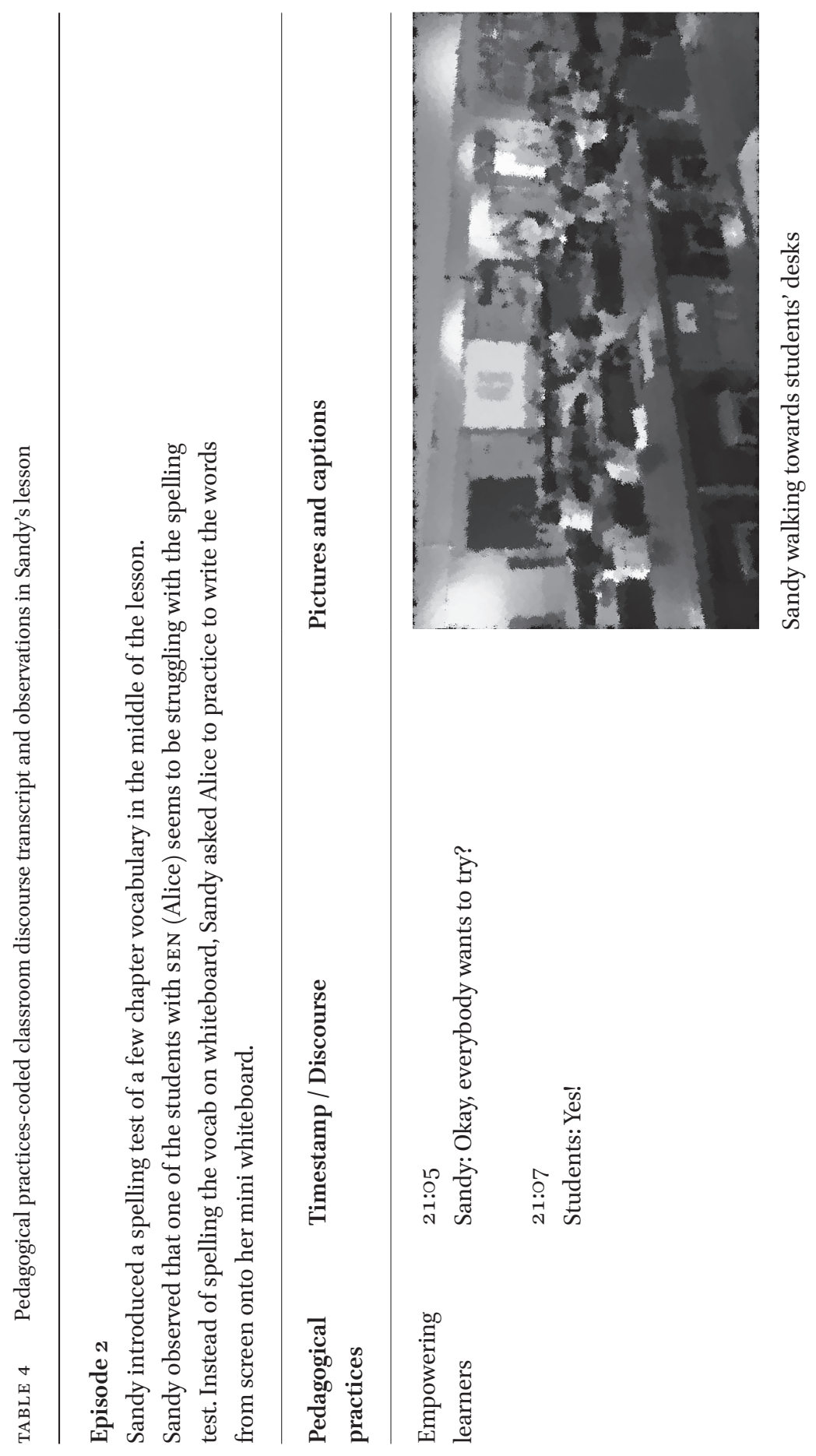




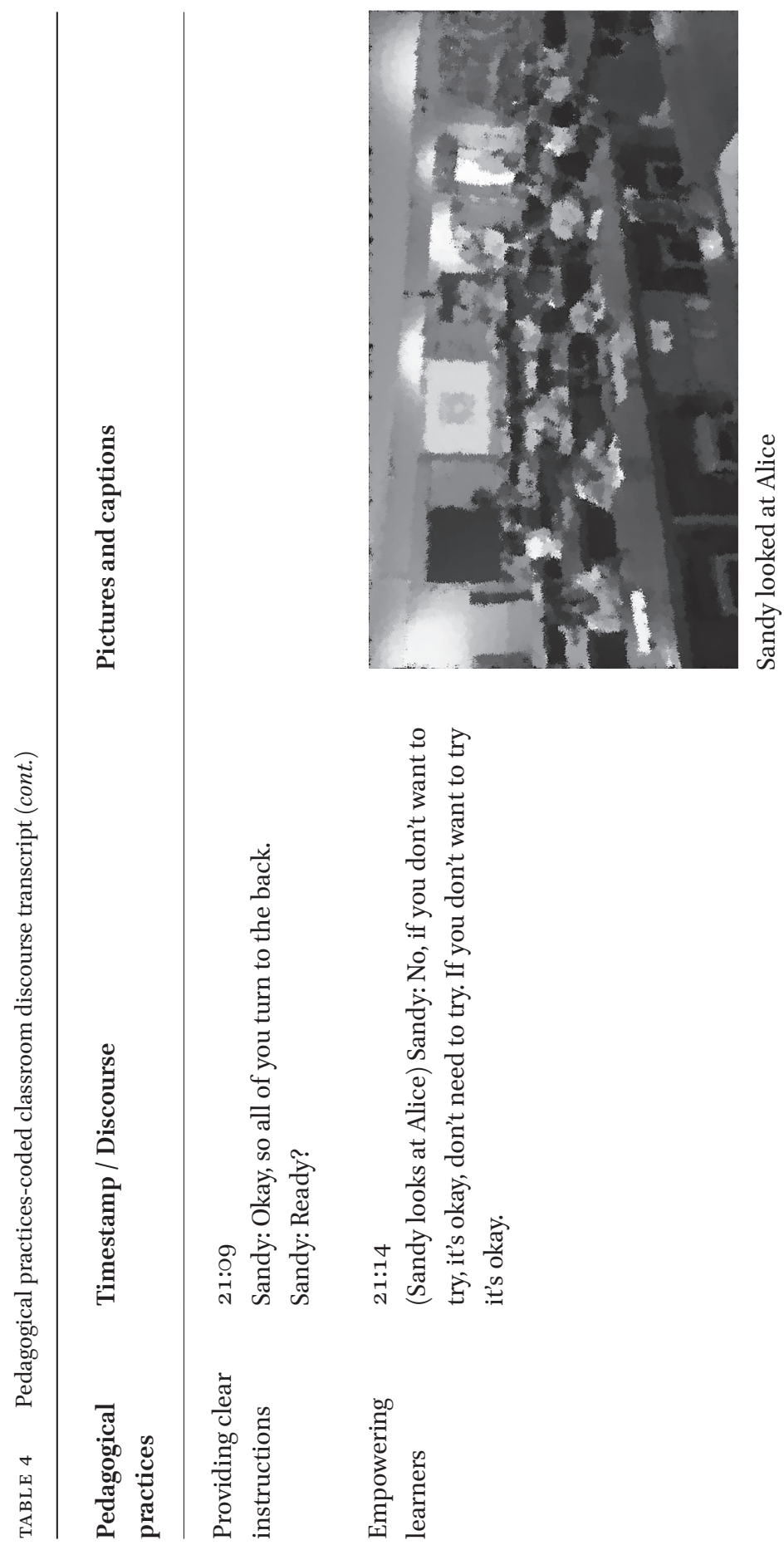




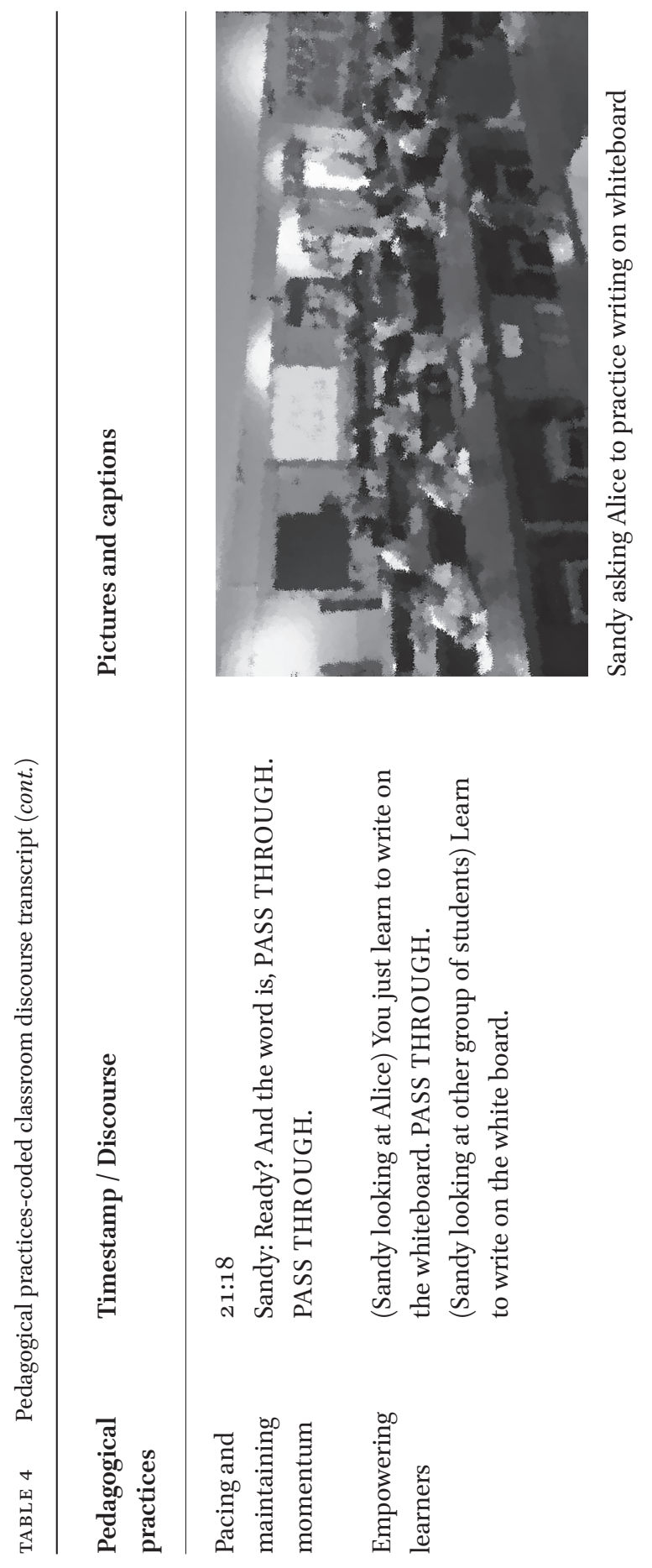




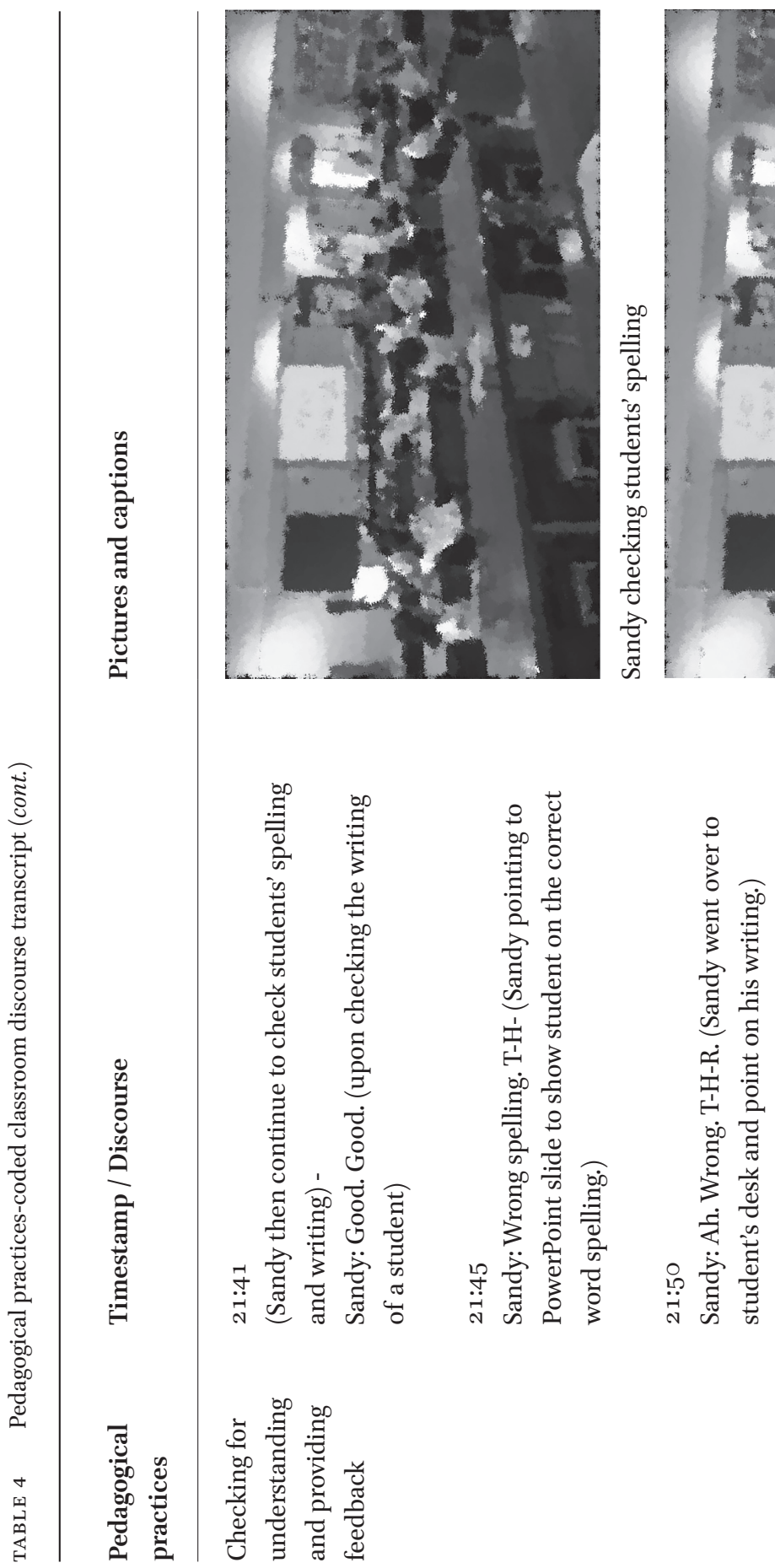




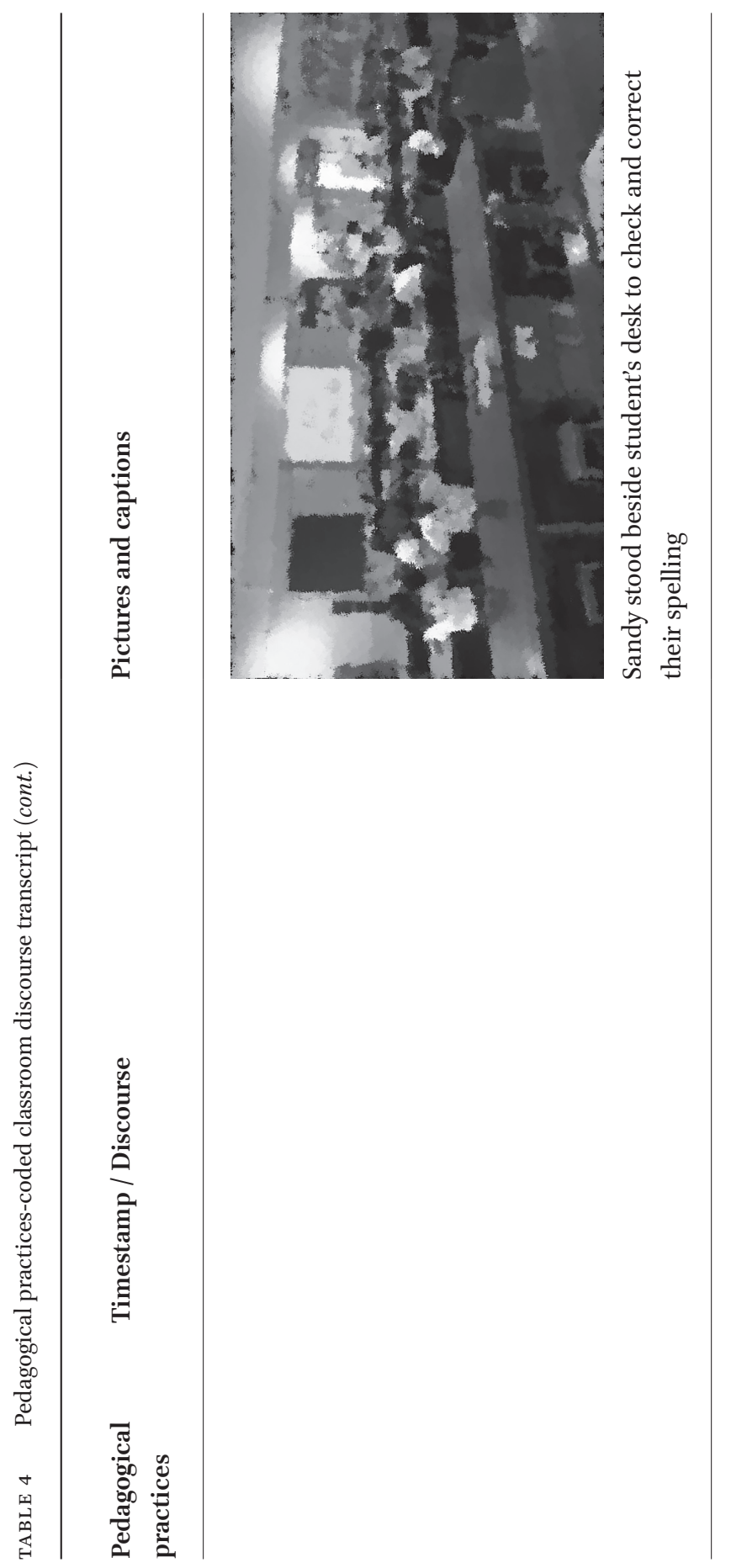




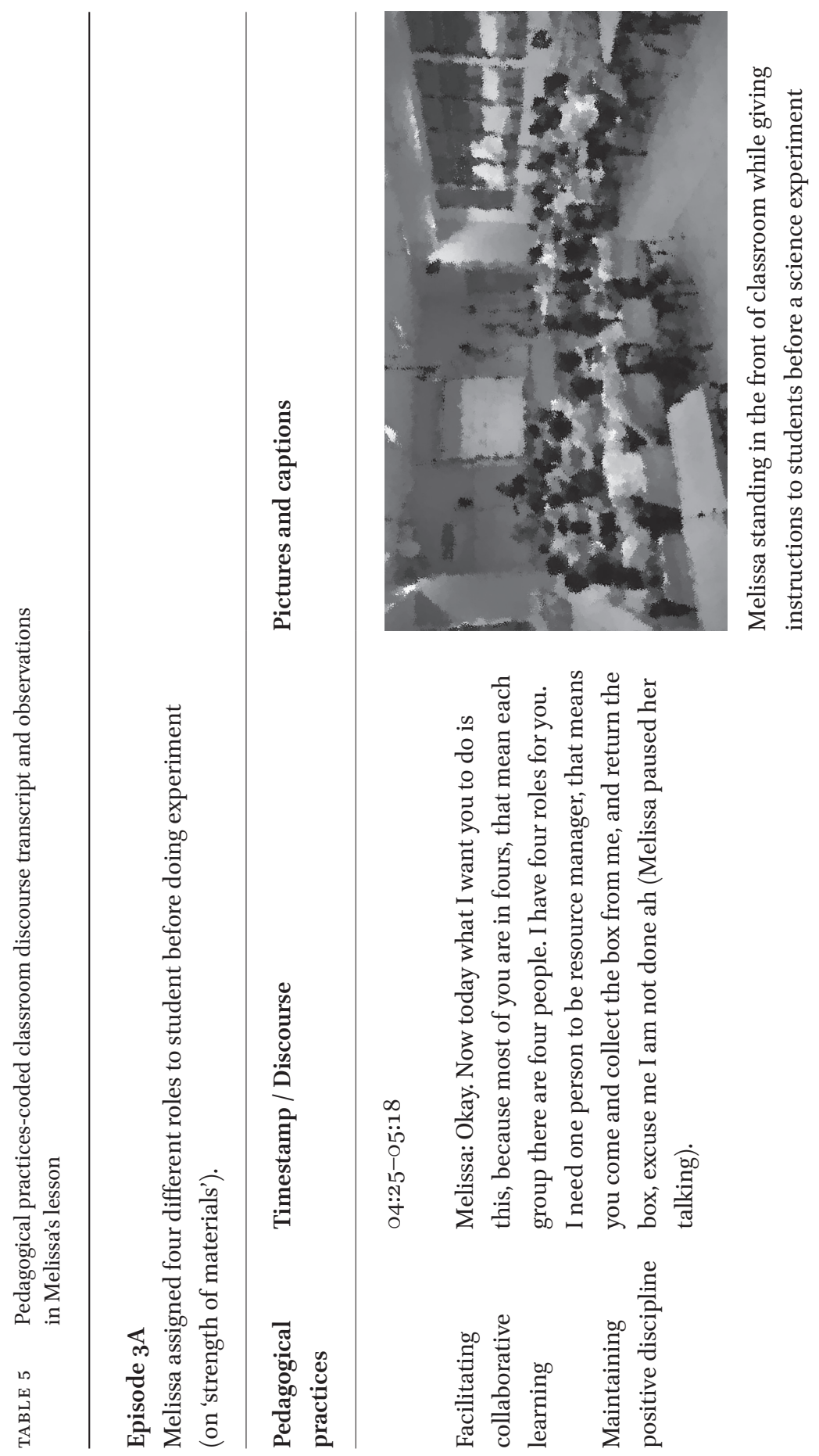




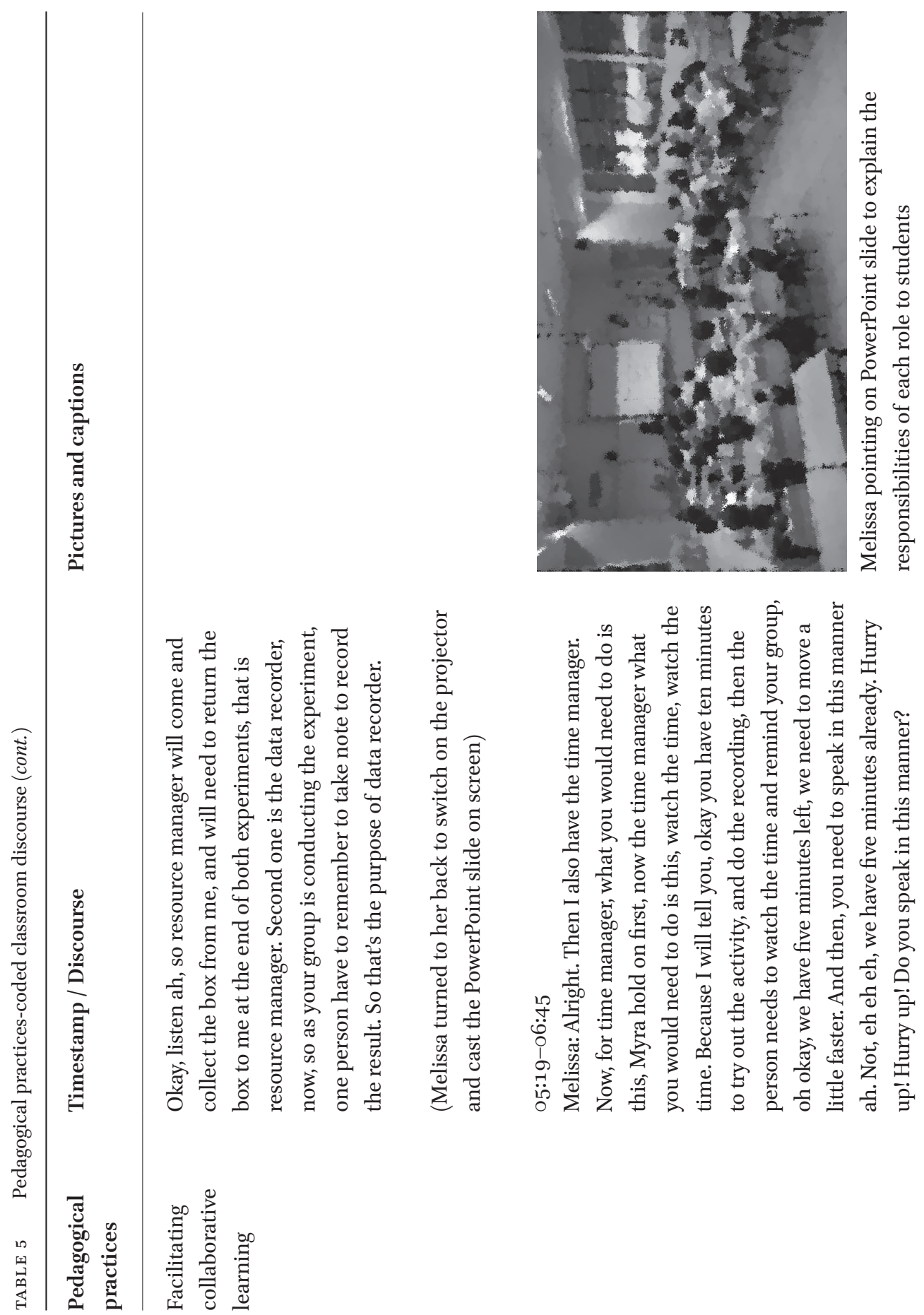




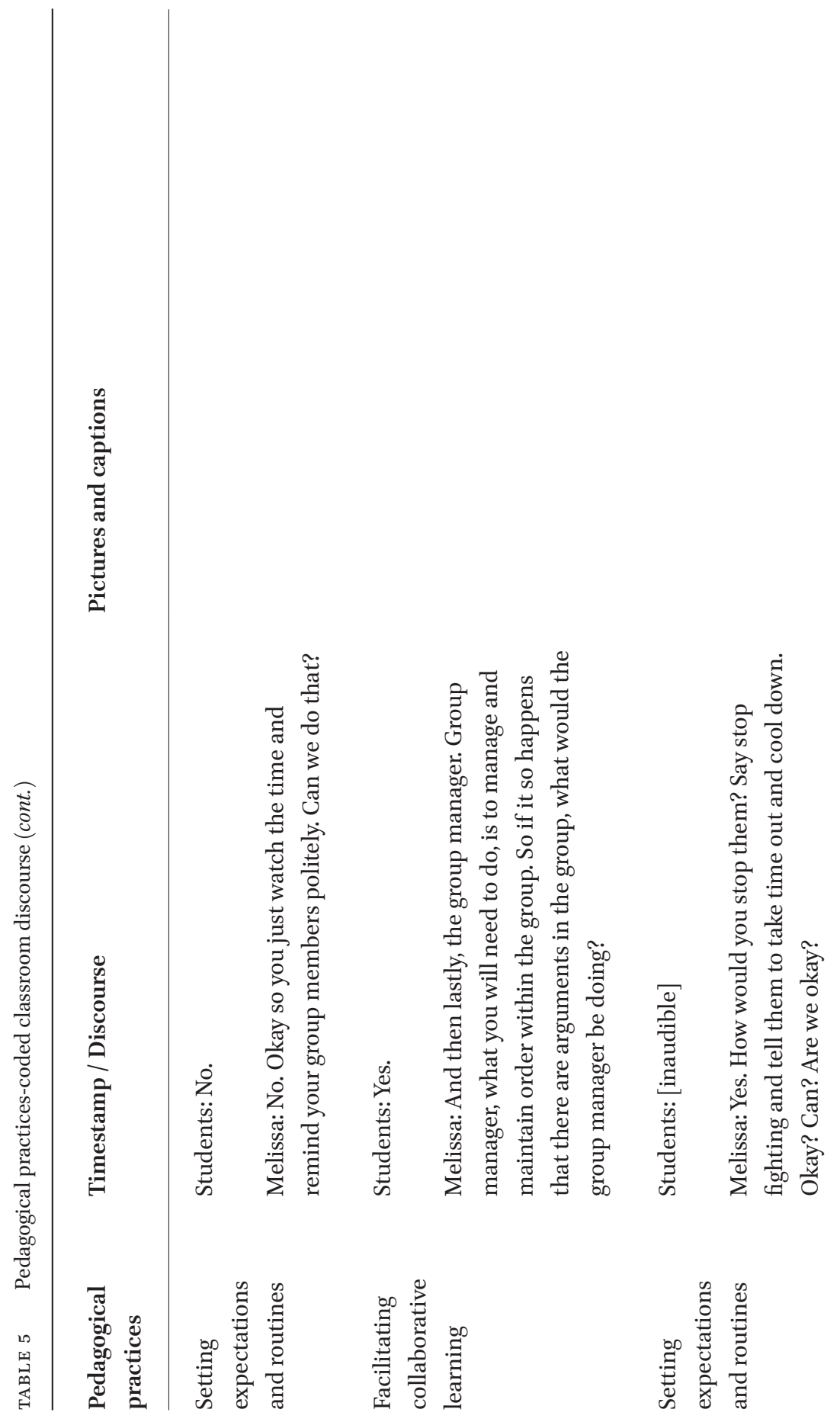




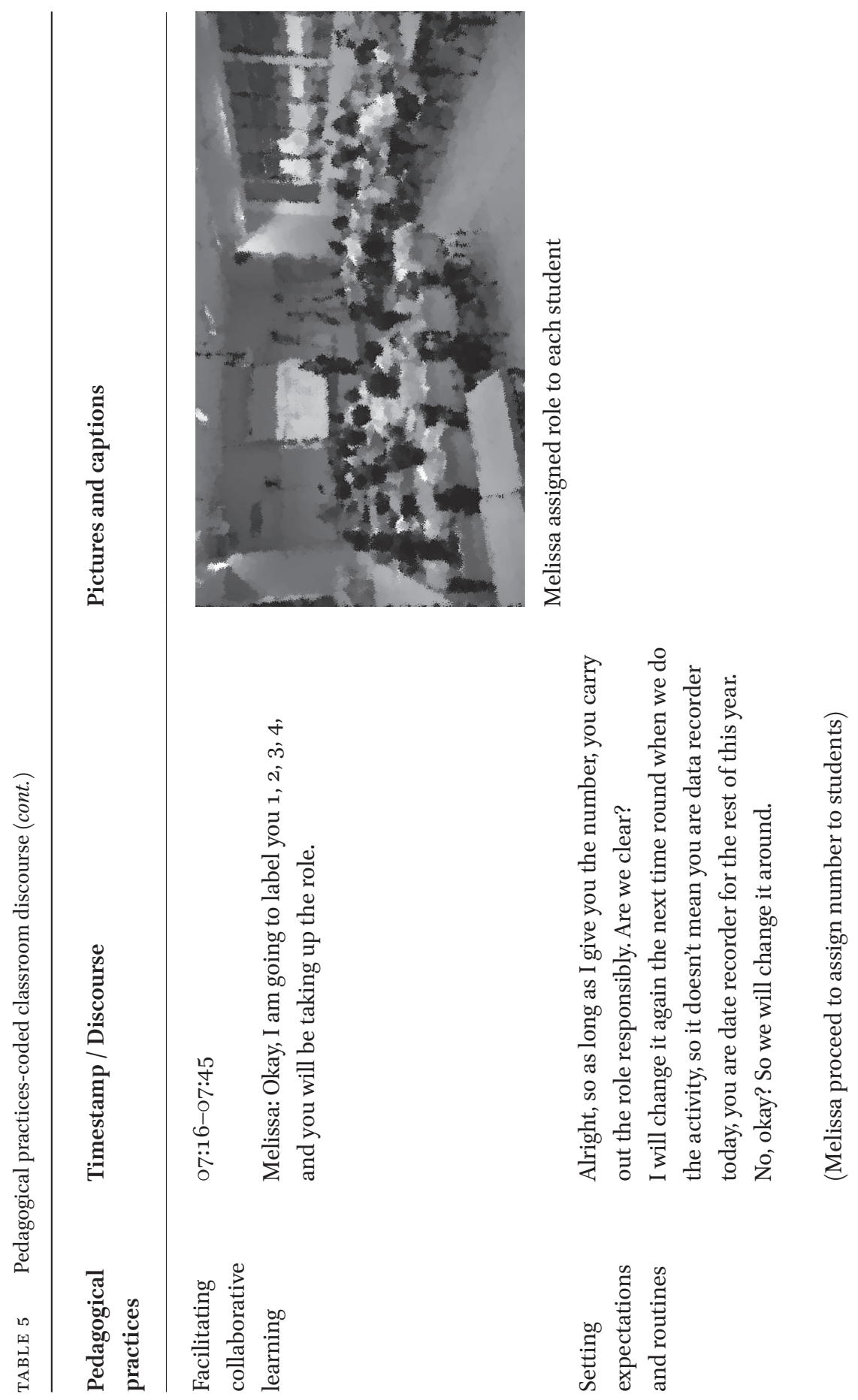




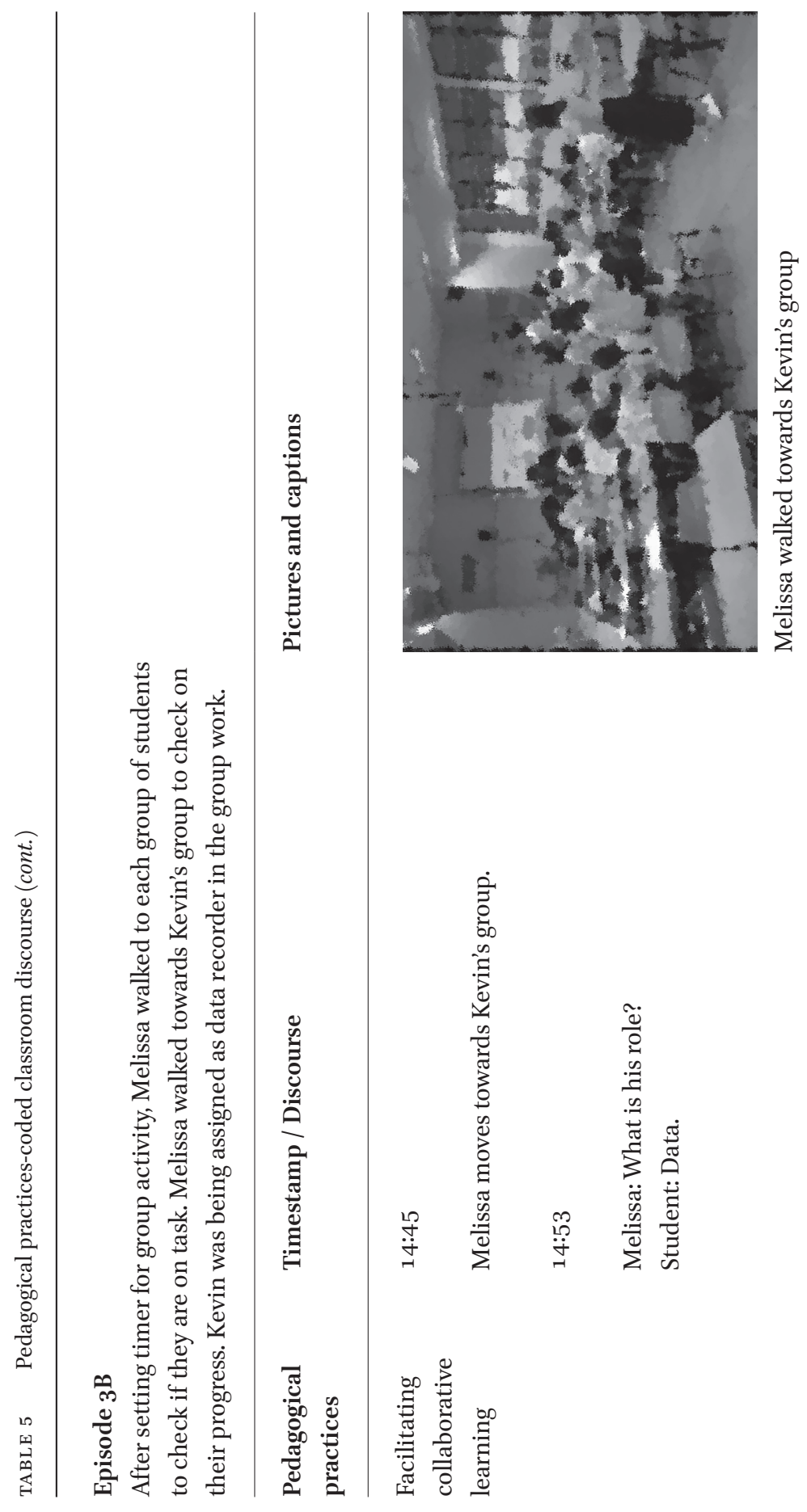




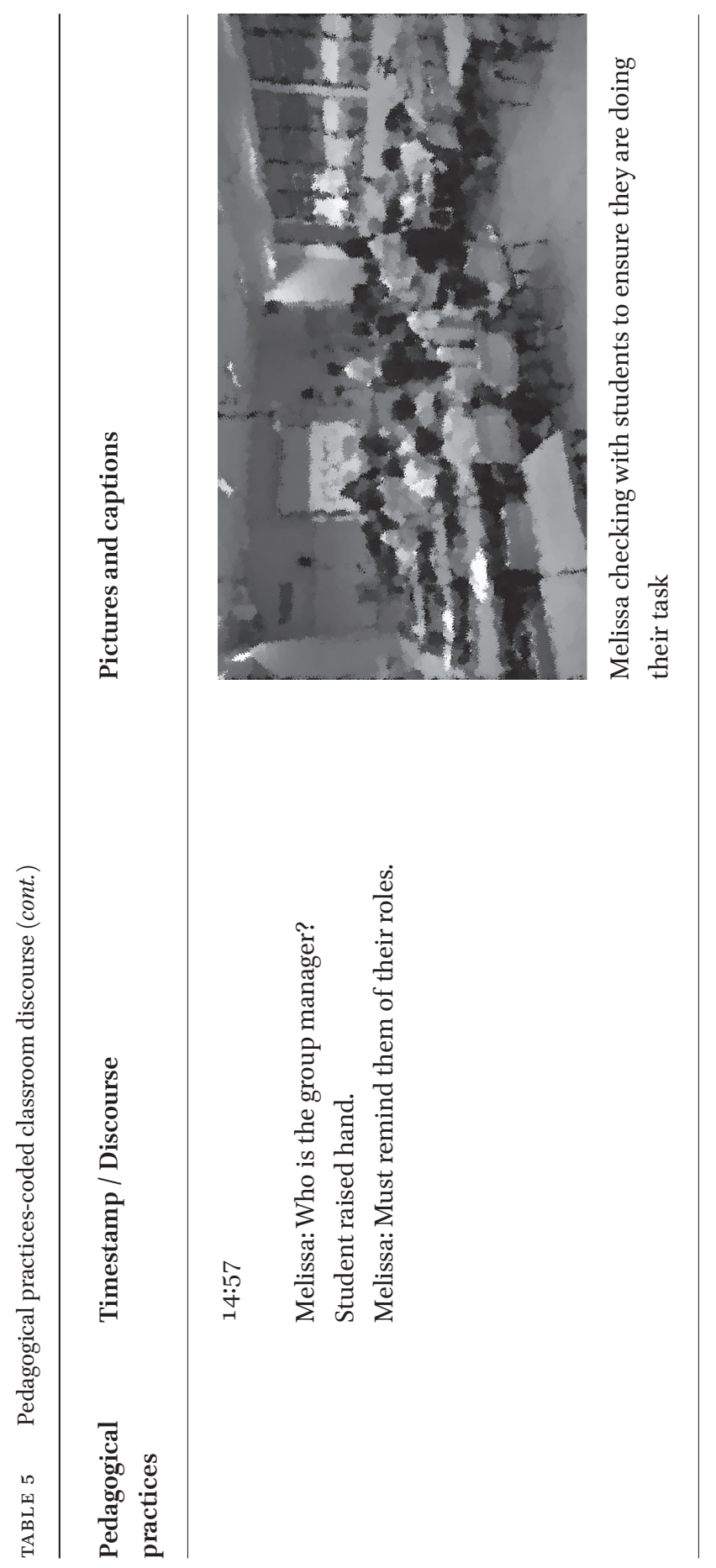




\subsubsection{Interpretive Commentary}

Episode 3 A. Melissa spent a significant amount of time in facilitating students' group work. Her briefing included a variety of pedagogical practices because of the different messages that she was putting across. These included telling students the different roles that they would play, while not forgetting to maintain positive discipline at the same when she observed students not paying attention to her instructions. She also discussed group etiquette as she addressed how the time manager could address the group members politely. She set her expectations and established rules. Notably, Cindy and Melissa had both taken up the suggestion from the research team to assign clear roles to students in group work. However, the teachers enacted it differently.

First, Cindy numbered the students before explaining the roles, while Melissa explained the roles before numbering the students. In the former, students would pay attention to what they were supposed to do and hence be more focused on their roles. However, the latter approach can allow every team member to learn about all the different roles, but they may not remember their own roles as clearly. Second, Melissa gave students the heads up that their roles would change in the next round of group work, but Cindy did not mention this. Telling students that they would play different roles in the future could appease students who preferred to perform a different task and help them learn about their own and their peers' roles, hence fostering more close-knit teamwork.

Episode $3 B$. Melissa followed up on the students' group work as she moved around to check on their progress. In this instance, it was interesting to note another difference between Melissa's and Cindy's approaches. As discussed earlier, Cindy approached Nicholas to check on his contributions. However, Melissa asked Kevin's group members about his role and identified the group manager whose role was to remind the group members about their task. The difference lay in the ownership of learning, as Cindy's actions were coded as 'empowering learners' while Melissa's act was coded as 'facilitating collaborative learning'. We distinguished these two pedagogical practices, as the ownership of learning responsibility was different (i.e., on the student with SEN versus the immediate circle of peers surrounding the student with SEN).

\subsection{Overall Commentary}

In summary, nine different pedagogical practices were identified in the three sets of episodes that we selected. While the intent of this analysis was not to quantify the number of pedagogical practices enacted, we noted that the nine pedagogical practices spanned across three of the four teaching processes: assessment and feedback, positive classroom culture, and lesson enactment. In this section, we address the second research question by making connections 
between the pedagogical practices enacted by the three teachers and the Inclusive Pedagogical Approach in Action (IPAA) framework (Florian 2014; Florian \& Spratt, 2013), which offers suggestions on pedagogical approaches that count as evidence of inclusive education.

First, the pedagogical practices adapted by the teachers had afforded opportunities for participation. The three teachers had considered all students in designing and enacting their science lessons. They did this by creating environments with appropriate conditions (guidelines, scope, and rules) so that every student, including Nicholas, Alice, and Kevin, could participate in the activities and learn. The group work and spelling formative assessment were activities that Nicholas, Alice, and Kevin could take part in, as these activities were extended to all learners in the same community. The three students could participate as full members with others. Differentiation was afforded by providing Alice with visual access to words that she could learn to spell from copying rather than from recall, as learning from recall would add an additional layer of challenge to her spelling difficulty. Alice was given the option to choose her entry level of participation.

Collaboration was possible because the students with SEN were distributed into different groups and not grouped according to ability. Their roles were assigned based on pre-planning with the specific goal of having Nicholas and Kevin contribute as active members. In all three cases, the emphasis on what they could achieve within their means and not what they could not do was empowering. The social constructivist approach to teaching was engaged in all three lessons as the three students were all tasked to take ownership of their own learning.

Fundamentally, two important ideas that showed inclusivity may be inferred from how the pedagogical practices were engaged: (a) Differences were accepted as part of the students' human condition. However, the condition that led to the identification of 'difference' did not become the reason for holding back the students' progress through participation. (b) The teachers held beliefs that the students with SEN could learn and make progress.

Second, the pedagogical practices enacted illuminated the teachers' interest in the welfare of the 'whole child' and not simply the acquisition of science content knowledge. For example, Melissa did not check with Kevin on whether he had fulfilled his role responsibly. Rather, she checked with Kevin's group mates to ensure that they had kept Kevin on his toes. In the process, Kevin's group mates would recognize Kevin as a member as they were responsible for peer support. Their acknowledgement was to Kevin, a signal of acceptance of him as a member of the group. Similarly, when Cindy checked on Nicholas, she did not immediately turn to look at his workbook. Rather, she checked 
with him to find out if he had completed his task responsibly. She spent a relatively longer time checking on Nicholas and interacting with him because she thought that it was important for him to show that he was willing to put in the effort. This was an indication of achievement. Although Sandy and Cindy co-taught a class, they understood the difficulties of students differently and planned for different topics to be taught, different materials, and methods of lesson delivery. This suggests that they had deliberated on the different needs of the students in their groups and chose to deliver their lesson flexibly rather than to seek efficiency in lesson preparation and enactment by sharing out the lessons and materials.

\section{6}

\section{Implications}

The findings of this study significantly contribute to the literature on and enactment of pedagogical practices toward creating a more inclusive environment for science learning. To reiterate the points earlier, inclusivity here refers to making resources available to the students with SEN so that they can participate, collaborate, achieve, receive recognition, and/or be accepted by others (Florian \& Hawkins, 2011). First, the study offers a contextual reconstruction of the term 'pedagogical practices' in the context of inclusive education where students with SEN attend mainstream schools and learn with other students in the same classrooms. Earlier, we provided a working definition of pedagogical practices. While generic, this definition seems to be detached from the discourse about inclusivity. Here, we offer a revised definition of pedagogical practices to underscore the spirit of inclusivity:

Pedagogical practices in inclusive education contexts encompasses the literal and symbolic moves, articulations, and objects, premised on a set of personal and professional attributes that value difference as the driver for the provision of education for all and for the whole child.

In the above definition, we positioned pedagogical practices as a force, mechanism, and means to address the need for inclusion in education contexts. This implies the reconstruction of pedagogical practices from being a performative, actionable, and observable act toward being an invisible form that requires deep thinking about the construct of 'difference'. By 'difference', we do not mean opposites, contrasts, or contradictions. Rather, we adopt the poststructuralist concept drawn from Derrida's (1978) work on 'difference' that makes use of binary thinking to underscore relationships and new ideas to emerge. 
We suggest that in adopting and enacting pedagogical practices for students with SEN, teachers can ask the questions, 'Is this pedagogical practice only for students with SEN or for all students in my class?' 'Does enacting this pedagogical practice further marginalize the students with SEN or make the lessons and learning opportunities more accessible to them?' Here, we surface the potential of pedagogical practices through the nuanced analysis of lesson episodes in event-oriented inquiry that illuminated 'difference' as the lens to drive the decisions on what and how pedagogical practices may be enacted to better support students in the acquisition and understanding of the abstract scientific jargon and expository style of scientific writing (Bakken, 1995). Referring to Chan and Lo's (2017) paper mentioned earlier, we want to reiterate the idea that pedagogical practice could be the force to promote social justice and fight exclusion. In Chan and Lo's work, they adopted personal narrativizing to surface this potential of pedagogical practices.

Second, the discussion in this paper contributes to the positioning of 'pedagogical practices as personal'. As a former science teacher, the first author has struggled with the dilemma of teaching, or not teaching, science to students with dyslexia, especially when it is textually challenging to learn the scientific jargon that is abstract. Other science teachers who struggle to support their students to learn science may be able to feel a resonance with this experience. The struggle to understand why science should be taught and how students with SEN may be supported to learn science was liberating and honed the first author's pedagogical practice in the science teaching of students with SEN. To borrow the phrase 'personal as political' (a slogan in the second wave of feminism by Hanisch, 1969) and Sim's (2004) work on 'pedagogical as personal', we think that the questions in the earlier paragraph reflect the conundrums that teachers often confront when they reflect on what they have enacted and make changes to their pedagogical practices when teaching in inclusive lessons. This is the idea about being reflexive (Lather, 1991), as opposed to being reflective, about one's practice. Reflexivity involves change in acting otherwise, while reflections reside in thoughts that do not necessarily translate into actions. Precisely, this study illuminates pedagogical practices as an outcome of considered deliberations in inclusive science lessons.

Science has been argued to be challenging for students with dyslexia to learn because of the way scientific text is written in an expository manner with unfamiliar text structures, is conceptually dense, contains complex vocabulary, and comes with an expectation of students' prior knowledge (Graesser, 2003). What is unique about science learning is the hands-on learning experience in the laboratory. Laboratory activity instructions are formatted differently from worksheets. What could science teachers do to support students 
with SEN to manage diverse textual demands across the classroom and laboratory contexts?

Returning to the IPAA Framework (Florian, 2014; Florian \& Sprutt, 2013) mentioned earlier, we offer the following features of inclusive pedagogical practices that could contribute to the reflexivity of science teachers by adapting their pedagogical practices to address inclusivity, especially when science teaching can happen in varied contexts that demand more pedagogical considerations be made and pedagogical practices be flexibly adapted to meet the diverse and unique needs of students of SEN in science learning contexts:

- Checking in writing or verbally for understanding demonstrated in science and providing feedback on the work rather than abilities of the student

- Maintaining positive discipline across contexts (i.e., science laboratory and classroom) that has an impact on the overall development of the child

- Setting realistic expectations and routines for students to experience success in the science laboratory and classroom

- Establishing interaction and rapport between teacher and students and between students for peer support in the absence of continued teacher support

- Empowering learners to acknowledge their own limitations and choose their mode of participation

- Facilitating collaborative learning by providing explicit and individual roles in the completion of science activities

- Encouraging students to contribute as full rather than peripheral members

- Pacing and maintaining momentum by adopting a flexible approach

- Providing clear instructions on what is to be completed and how to complete it, rather than who is to learn what

\section{Conclusion}

This paper reported on pedagogical practices enacted to address inclusivity in three case studies in science learning contexts in Singapore. This work made reference to the Singapore Teaching Practice to unpack the pedagogical practices that unfolded when inclusive strategies were adopted by teachers following feedback on baseline lessons. In the event-oriented inquiry of three sets of episodes, nine pedagogical practices were identified and these were enacted in ways that aligned to the spirit of inclusivity. When enacted, opportunities for participation, collaboration, and achievement were afforded to the students with SEN to learn science. Based upon our findings, we built on the literature on pedagogical practices by offering an inclusivity-contextualized definition. We 
also offered ideas on adaptations of the nine pedagogical practices to enhance the reflexive practices of teachers teaching in inclusive science lessons.

\section{Limitations of the Study}

While the analysis has provided some illustrative insights into how inclusive science practices unfolded in science classrooms with students with dyslexia, we are cognizant that the discussion does not address all the pedagogical practices. In many classrooms, there could be more than one student with SEN, and students can have a variety of SEN. Hence, it may not be clear how the other pedagogical practices will play out in the classroom. The events may thus unfold differently in these contexts. Given the limited number of studies in this area of work, it will be beneficial to conduct more research in inclusive classrooms that provide more proximal insights into what science teachers can do to manage the demands of science teaching and the needs of students with SEN by adapting specific pedagogical practices and reflecting on the affordances and constraints such practices present to students.

\section{Acknowledgements}

This study was funded by Singapore Ministry of Education (MOE) under an ERFP grant (OER25/17TTW) and administered by the National Institute of Education (NIE), Nanyang Technological University, Singapore. Any opinions, findings, conclusions, and recommendations expressed in this material are those of the author(s) and do not necessarily reflect the views of the Singapore MOE and NIE. Approval to conduct this study was granted by the Nanyang Technological University (Singapore) Institutional Review Board (IRB-201805-O57) and Ministry of Education (EDUN N32-07-005). The data collected from this project were obtained with the necessary clearance from the partner institutions, guardians, and the students involved in the study. The names of the school and participants used in this study are all pseudonyms. We had obtained permission to use participant images in publications.

\section{Abbreviations}

APSE Asia Pacific Science Education

DPA Disabled People's Association 


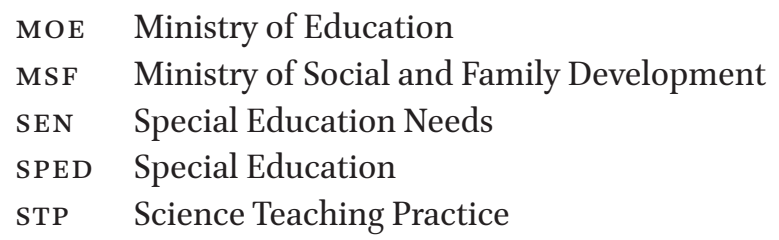

\section{Funding}

This study was funded by Singapore Ministry of Education (MOE) under the ERFP grant (OER25/17TTW) and administered by National Institute of Education (NIE), Nanyang Technological University, Singapore. Any opinions, findings, and conclusions or recommendations expressed in this material are those of the author(s) and do not necessarily reflect the views of the Singapore MOE and NIE.

\section{Ethical Considerations}

Approval to conduct this study was granted by the Nanyang Technological University (Singapore) Institutional Review Board (IRB-2018-05-057) and Ministry of Education (EDUN N32-07-005). The data collected from this project were obtained with the necessary clearance from the partner institutions, guardians, and the students involved in the study. The names of the school and participants used in this study are all pseudonyms. We obtained permission to use participant images in publications.

\section{About the Authors}

Tang Wee Teo is an Associate Professor in the Natural Sciences and Science Education (Academic Group), National Institute of Education (NIE), Nanyang Technological University, Singapore. She is also the Co-Head of the Multi-centric Education, Research and Industry STEM Centre at NIE (meriSTEM@NIE). She graduated from the University of Illinois, Urbana-Champaign, in 2011. Prior to her doctoral studies, she was a chemistry teacher in a high school and a specialized STEM school for gifted mathematics and science students. An equity scholar in STEM education, her research focuses on issues of inclusivity in classrooms with under achievers and students with special education needs. She has received the Asia-Pacific Science Education Best Paper Award in Jan 
2021 for her paper about special needs science education. She also studies gender issues in STEM education. She has published a chapter about an evaluation study of a STEM programs for girls in a UNESCO report. She is the Founding Editor-in-Chief of Research in Integrated sтEM Education.

Ching Yee Pua was a Research Assistant of the National Institute of Education (NIE), Nanyang Technological University, Singapore. She was responsible for the data collection and transformation of the study. Ching Yee's role was instrumental in forging good researcher-participant relationship throughout the study.

\section{References}

Bakken, J. P. (1995). Reading comprehension of expository science material and students with learning disabilities: A comparison of strategies. Published dissertation with ProQuest. Retrieved on August 10, 2021 from https://www.proquest.com/open view/597886oe39ao937ab6bc57e16ddf94eb/1.pdf/advanced.

Chan, C., \& Lo, M. (2017). Exploring inclusive pedagogical practices in Hong Kong elementary EFL classrooms. International Journal of Inclusive Education, 21(7), 714-729. doi:10.1080/13603116.2016.1252798.

Chin, C. (2006). Teacher questioning in science classrooms: Approaches that stimulate productive thinking. Journal of Research in Science Teaching, 44(6), 815-843.

Derrida, J. (1978). Writing and Difference, trans. Alan Bass, Chicago: University of Chicago Press.

Disabled People's Association. (2016). Achieving inclusion in education: Understanding the needs of students with disabilities. Retrieved on May 21, 2021 from http://www .dpa.org.sg/wp-content/uploads/2016/o7/Incusion-in-Education.pdf.

Dominguez, O., \& Carugno, P. (2020). Learning disability. Retrieved on May 21, 2021 from https://www.ncbi.nlm.nih.gov/books/NBK554371/.

Dyslexia Association of Singapore (n.d.). Towards understanding dyslexia: how parents can help. Retrieved on May 21, 2021 from https://das.org.sg/news-events/blogs/35 -parenting-tips/495-towards-understanding-dyslexia-how-parents-can-help.html.

Florian, L. (2014). What counts as evidence of inclusive education? European Journal of Special Needs Education, 29(3), 286-294, DOI:10.1080/08856257.2014.933551.

Florian, L., \& Hawkins, K. B. (2011). Exploring inclusive pedagogy. British Educational Research Journal, 37(5), 813-828.

Florian, L., \& Spratt, J. (2013). Enacting inclusion: A framework for interrogating inclusive practice. European Journal of Special Needs Education: Teacher Education for Inclusion, International Perspectives, 28(2), 119-135. DOI:10.1080/08856257.2013 .778111 . 
Hennessy, S., \& Deaney, R. (2009). The impact of collaborative video analysis by practitioners and researchers upon pedagogical thinking and practice: A follow-up study. Teachers and Teaching, 15(5), 617-638. DoI:10.108o/135406oo9o3139621.

Lather, P. (1991). Deconstructing/deconstructive inquiry: The politics of knowing and being known. Educational Theory, 41(2), 153-173, https://doi.org/10.1111/j.1741 $-5446.1991 .00153 \cdot x$.

Lee, M.-H., Wu, Y.-T., \& Tsai, C.-C. (2009). Research trends in science education from 2003 to 2007: A content analysis of publications in selected journals. International Journal of Science Education, 31(15), 1999-2020. DOI: 10.1080/0950069o802314876.

Mastropieri, M. A. \& Scruggs, T. E. (1998). Enhancing School Success with Mnemonic Strategies. Intervention in School and Clinic, 33(4), 201-208. Dor:10.1177/1053451298 03300402 .

Ministry of Education. (2020). SkillsFuture for educators. Retrieved on September 8, 2021 from https://www.moe.gov.sg/microsites/cos2020/skillfuture-for-educators.html.

Ministry of Education. (2021a). The Singapore teaching practice. Retrieved on August 2, 2021 from https://www.moe.gov.sg/education-in-sg/our-teachers.

Ministry of Education (2021b). Support in mainstream schools. Retrieved on May 21, 2021 from https://www.moe.gov.sg/special-educational-needs/school-support/ mainstream/.

Ministry of Education (2021b). Overview of compulsory education. Retrieved on September 8, 2021 from https://www.moe.gov.sg/primary/compulsory-education/ overview.

Ministry of Social and Family Development (MSF) (2016). 3rd Enabling Masterplan 2017-2021: Caring Nation, Inclusive Society. Retrieved on April 28, 2020 from https://www.enablingguide.sg/docs/default-source/publications/enabling -masterplan-3-(revised-13-jan-2017).pdf?sfvrsn=bo5da8ae_2.

National Council of Social Service (2020). Adults with disabilities. Retrieved April 28, 2020 from https://www.ncss.gov.sg/GatewayPages/Social-Services/Adult -with-Disabilities.

Rapoport, A. (2008). The impact of international programs on pedagogical practices of their participants: A Russian experience. Teachers and Teaching, 14(3), 225-238. DOI:10.1080/13540600802006129.

Scruggs, T. E., \& Mastropieri, M. A. (1993). Current approaches to science education: Implications for mainstream instruction for students with disabilities. Remedial and Special Education, 14, 15-24.

Shulman, L. S. (1996). Paradigms and research programs in the study of teaching: A contemporary perspective. In M. C. Wittrock (Ed.), Handbook of research on teaching 3 rd ed. (pp. 3-36). New York, NY: Macmillan.

Sim, C. (2004). The personal as pedagogical practice. Teachers and Teaching, 10(4), 351-364. DOI:10.1080/1354060042000224115. 
Teo, T. W. (2013). Examining the performative quality of a teachers' curriculum reform making through a metaphorical lens. Education as Change: Journal of Curriculum Research, 17(1), 89-100.

Teo, T. W. (2021). A Survey of Science Teachers' Perception and Practices in Inclusive Science Classrooms. Asia-Pacific Journal of Science Education, 6(2), 388-426.

Tobin, K. (2014). Twenty questions about cogenerative dialogues. In K. Tobin \& A. Shady (Eds.), Transforming urban education (pp. 181-19o). Rotterdam: SensePublishers.

World Health Organisation (2021). Autism spectrum disorders. Retrieved on September 8, 2021 from https://www.who.int/news-room/fact-sheets/detail/autism -spectrum-disorders.

Zwart, R. C., Wubbels, T., Bergen, T. C. M. \& Bolhuis, S. (2007). Experienced teacher learning within the context of reciprocal peer coaching. Teachers and Teaching: theory and practice, $13(2), 165^{-187}$. 